2-Arachidonoylglycerol mobilization following brief synaptic stimulation in the dorsal lateral striatum requires glutamatergic and cholinergic neurotransmission

Daniel J. Liput1,2, Henry L. Puhl1, Ao Dong3-5, Kaikai He³,4, Yulong Li3-6, David M. Lovinger²

1'Laboratory of Molecular Physiology and 2Laboratory for Integrative Neuroscience, National Institute on Alcohol Abuse and Alcoholism, National Institutes of Health, Maryland, USA

${ }^{3}$ State Key Laboratory of Membrane Biology, Peking University School of Life Sciences, Beijing, China. 4PKU-IDG/McGovern Institute for Brain Research, Beijing, China. 5Peking-Tsinghua Center for Life Sciences, Beijing, China. ${ }^{6}$ Chinese Institute for Brain Research, Beijing, China

\title{
Abstract
}

Several forms of endocannabinoid (eCB) signaling have been described in the dorsal lateral striatum (DLS), however most experimental protocols used to induce plasticity do not recapitulate the firing patterns of striatal-projecting pyramidal neurons in the cortex or firing patterns of striatal medium spiny neurons. Therefore, it is unclear if current models of eCB signaling in the DLS provide a reliable description of mechanisms engaged under physiological conditions. To address this uncertainty, we investigated mechanisms of eCB mobilization following brief synaptic stimulation that mimics in vivo patterns of neural activity in the DLS. To monitor eCB mobilization, the novel genetically encoded fluorescent eCB biosensor, GRABeCB2.0, was expressed in corticostriatal afferents of C57BL6J mice and evoked eCB transients were measured in the DLS using a brain slice photometry technique. We found that brief bouts of synaptic stimulation induce long lasting eCB transients. Inhibition of monoacylglycerol lipase, prolonged the duration of the $\mathrm{CCB}$ transient, while inhibition of diacylglycerol lipase inhibited the peak amplitude, suggesting that 2-AG is the predominate eCB generated following brief synaptic stimulation. 2-AG transients were robustly inhibited by AMPA and NMDA receptor antagonists, DNQX and DL-AP5 respectively. Additionally, the 2- 
30 AG transient was inhibited by the muscarinic M1 receptor (M1R) antagonist, VU

31 0255035, and augmented by the M1R positive allosteric modulator, VU 0486846 ,

32 indicating that acetylcholine (ACh) release is required for efficient 2-AG production. The

33 dopamine D2 receptor (D2R) agonist, quinpirole, inhibited the 2-AG transient. However,

34 in slices from mice lacking D2Rs on cholinergic interneurons (CINs), quinpirole did not

35 inhibit the 2-AG transient, demonstrating that D2Rs on CINs can modulate 2-AG

36 production. The AMPA receptor or NMDA receptor antagonists, DNQX or DL-AP5

37 respectively, occluded 2-AG augmentation by VU 0486846 suggesting that converging

38 glutamatergic and cholinergic signals are required for efficient 2-AG production following

39 brief synaptic stimulation. Collectively, these data uncover unrecognized mechanisms

40 underlying 2-AG mobilization in the DLS.

Introduction

The endocannabinoids (eCBs) are lipid-derived signaling molecules that play a

44 major role in synaptic modulation in the central nervous system (CNS). Unlike traditional

45 neurotransmitters that are released from presynaptic vesicles, the eCBs are produced

46 via enzymatic catalysis of arachidonate-containing precursor phospholipids in the

47 plasma membrane (Ueda et al., 2013) and subsequently released from cells via a non-

48 vesicular mechanism (Wilson and Nicoll, 2001). In the most common scenario, lipid

49 metabolism occurs in the postsynaptic membrane and the eCBs traverse the synaptic

50 cleft to stimulate CB1 receptors (CB1R) on presynaptic terminals, leading to inhibition of

51 neurotransmitter release (Kano, 2014; Kreitzer and Regehr, 2001; Lovinger, 2008; 
52 Ohno-Shosaku et al., 2001; Wilson and Nicoll, 2001). The predominant mobilization

53 mechanism for the two main eCBs, 2-arachidonoylglycerol (2-AG) and

54 arachidonoylethanolamide (Anandamide, AEA), is production and release "on demand"

55 in response to membrane depolarization and subsequent $\mathrm{Ca}^{2+}$ influx, and/or activation

56 of $\mathrm{Ga}_{\mathrm{q} / 11}$ by g-protein coupled receptors (GPCRs). Indeed, these biochemical

57 mechanisms underlie several forms of eCB-dependent synaptic modulation including

58 short-term depression (STD) and long-term depression (LTD) at glutamatergic and

59 GABAergic synapses. However, there is also evidence for tonic eCB production and

60 signaling (Lee et al., 2010; Lee et al., 2015; Neu et al., 2007; Wilson and Nicoll, 2001).

The kinetics of eCB signaling have not been measured directly on time scales

62 supporting synaptic modulation, but estimates have been proposed based on the onset

63 and decay of eCB-dependent STD (Heinbockel et al., 2005). This measure involves not

64 only the kinetics of extracellular eCB increases, but also the timing of receptor activation

65 and presynaptic effector changes. Furthermore, although these estimates may be

66 accurate for depolarization-induced suppression of inhibition (DSI) and other types of

67 STD, the timing and magnitude of eCB signaling may not be universal for all forms of

68 eCB-dependent plasticity and may not be the same for 2-AG and AEA. Additionally, the

69 kinetics of eCB signaling and the physiological consequences do not always correlate.

70 For example, LTD at corticostriatal and hippocampal synapses lasts for more than an

71 hour but becomes resistant to CB1R antagonists minutes after induction (Chevaleyre

72 and Castillo, 2003; Ronesi et al., 2004; Yin et al., 2006). Therefore, strategies other 
73 than measuring plasticity kinetics are required to accurately measure eCB mobilization

74 underlying physiological phenomena of interest.

CB1Rs and the appropriate eCB synthesis and degradation enzymes are abundantly expressed in the dorsal lateral striatum (DLS), and indeed multiple forms of eCB-dependent depression have been described in this brain region (Calabresi et al., 2007; Mathur and Lovinger, 2012). Perhaps the most well characterized form, LTD at corticostriatal synapses, can be induced by either high frequency stimulation

81 (LFS)(Ronesi and Lovinger, 2005). Interestingly, these two stimulation protocols may

82 induce LTD by differentially mobilizing AEA or 2-AG, suggesting that different modes of

83 eCB signaling can be engaged depending on the amount of neural activity (Lerner and Kreitzer, 2012). Although HFS or long bouts of LFS result in eCB-LTD in the DLS, these stimulation patterns do not accurately recapitulate the in vivo firing patterns of striatalprojecting pyramidal neurons in the cortex or firing patterns of medium spiny neurons (MSNs) in the striatum (Costa et al., 2004). In other brain regions, eCB-dependent plasticity can be induced by brief bouts of synaptic stimulation (Brown et al., 2003;

Galante and Diana, 2004; Maejima et al., 2001; Maejima et al., 2005), and eCBs should also be mobilized by physiologic patterns of afferent stimulation in the DLS.

92 vivo and in vivo models. In particular, intensity-based genetically encoded biosensors,

93 based on the GPCR scaffold, are being implemented to uncover unrecognized

94 physiological mechanisms across multiple neurotransmitter systems (Liang et al., 2015; 
95 Mizuno et al., 2019; Ravotto et al., 2020; Wang et al., 2018). These new generation

96 sensors have several desirable characteristics including; inherent ligand specificity and

97 affinity, rapid reporting dynamics, high spatial resolution, cellular targeting capability,

98 and disabled effector coupling. A novel biosensor engineered on the GPCR platform,

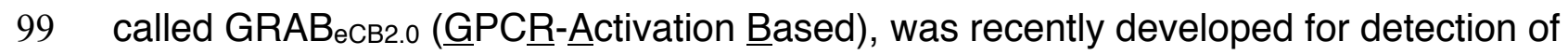

100 eCBs (Dong et al., 2020). This sensor was engineered by inserting a circular

101 permutated GFP into the third intracellular loop of human CB1R and can thus report on

102 both 2-AG and AEA signaling. We used this sensor in an ex vivo brain slice photometry

103 technique to study eCB mobilization kinetics, neural activity rules supporting eCB

104 generation, and neurochemical pathways underlying eCB synthesis and degradation in

105 the striatum.

107 Materials and Methods

108 Animals

All animal studies were conducted in accordance with the National Institutes of

110 Health's Guidelines for Animal Care and Use and all experimental protocols were

111 approved by the National Institute on Alcohol Abuse and Alcoholism Animal Care and

112 Use Committee. C57BL/6J and ChAT-IRES-Cre (B6.129S-Chattm1(cre)Lowl/MwarJ, Stock

113 No: 031661) mice (8-10 weeks) were ordered from The Jackson Laboratory (Bar

114 Harbor, ME, USA). Drd2 ${ }^{\text {LoxP/LoxP(Drd2 }}{ }^{\text {tm1Mrub}}$ (Bello et al., 2011)) mice were maintained in

115 house on a C57BL/6J background. To generate mice lacking D2Rs in cholinergic

116 interneurons, mice heterozygous for the ChAT-IRES-Cre allele and homozygous for the 
117 Drd2LoxP allele (Drd2LoxP/LoxPChATIRES-Cre/WT) were bred with mice homozygous for the

118 Drd2LoxP allele (Drd2 LoxP/LoxP). Genotypes were determined by polymerase chain

119 reaction (PCR) using genomic DNA from ear biopsies.

121 Viral vectors

AAV2/9.hSyn.GRAB ecB2.0.WPRE.hGHpolyA (Titer: $1.0 \times 10^{13} \mathrm{GC} / \mathrm{mL}$ ) and

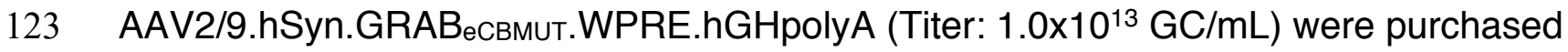

124 from Vigene Biosciences (Rockville, MD, USA).

125 AAV2/9.hSyn.GRABACh3.o.WPRE.hGHpolyA (Titer: $2.4 \times 10^{13} \mathrm{GC} / \mathrm{mL}$ ) was packaged in

126 house as described below. All viruses were aliquoted and stored at $-80^{\circ} \mathrm{C}$.

Viral production

AAV vectors were produced using a helper free triple transfection procedure

130 similar to that previously described (Xiao et al., 1998). 293AAV cells (Cell Biolabs, Inc)

131 were cultured in Dulbecco's modified Eagle's medium (DMEM) with GlutaMAX

132 (ThermoFisher, Waltham, MA, USA) and supplemented with non-essential amino acids

133 (NEAA, Gibco $\left.{ }^{\mathrm{TM}}\right), 10 \%$ FBS $\left(\right.$ Gibco $\left.^{\mathrm{TM}}\right)$ and antibiotics $(100 \mu \mathrm{g} / \mathrm{mL}$ penicillin and $\mu \mathrm{g} / \mathrm{mL}$

134 streptomycin, Gibco $\left.{ }^{\mathrm{TM}}\right)$. Cells were seeded at a density of $\sim 80 \%$ in T175 tissue culture

135 flasks and transfected with $0.165 \mu \mathrm{gDNA} / \mathrm{cm}^{2}$ in a $1: 1: 1$ molar ratio of

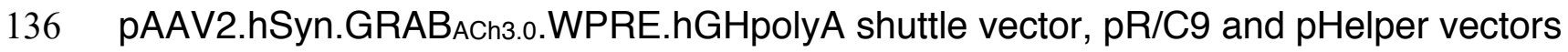

137 (Cell Biolabs, San Diego, CA) complexed to polyethylenimine (PEI) (N/P ratio = 5). After

$13872 \mathrm{hr}$ cells were harvested, resuspended in FBS-free DMEM and lysed by repeated 
139 freeze/thaw cycles. The lysate was centrifuged at 10,000g for 20 min and the cleared

140 supernatant was collected and incubated with benzonase $(50 \mathrm{U} / \mathrm{mL}$, Sigma-Aldrich, St

141 Louis, MO, USA) for $1 \mathrm{hr}$ at $37^{\circ} \mathrm{C}$. The cleared supernatant was then subject to

142 ultracentrifugation through an iodixanol density gradient similar to previously described

143 techniques (Strobel et al., 2015). lodixanol gradients were layered in $13.2 \mathrm{~mL}$ thin wall

144 tubes (14 x 89 mm, Beckman Coulter, Indianapolis, IN, USA). The lodixanol steps were

145 layered in the following order: $1 \mathrm{~mL} 60 \%$ iodixanol, $1.8 \mathrm{~mL} 40 \%$ iodixanol, $2.2 \mathrm{~mL} 25 \%$

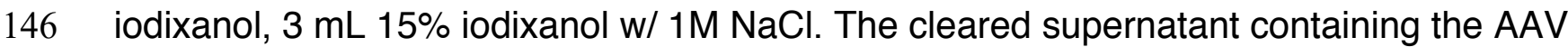

147 particles was layered on top of the gradient and centrifuged in a SW41 rotor (Beckman

148 Coulter) at $41,000 \mathrm{RPM}$ for $4.5 \mathrm{hr}$ at $10^{\circ} \mathrm{C}$. After ultracentrifugation, the $40 \%$ iodixanol

149 layer containing purified AAV particles was collected and the iodixanol was exchanged

150 for dPBS and concentrated to $100 \mu \mathrm{L}$. The AAV sample was passed through a $0.22 \mu \mathrm{m}$

151 filter and analyzed by silver stain and quantitative PCR (qPCR).

An aliquot of purified virus was serial diluted, denatured in 1 M DDT and $1 \mathrm{x}$ lane

153 marker for $5 \mathrm{~min}$ at $90^{\circ} \mathrm{C}$, and electrophoresed on a polyacrylamide gel. Gels were

154 stained using a Pierce ${ }^{\mathrm{TM}}$ silver stain kit according to the manufacturer's instructions

155 (ThermoFisher) and imaged using a FluorChem E system (ProteinSimple, San Jose,

156 CA, USA). The presence of AAV particles was confirmed by visualization of the VP1,

157 VP2 and VP3 capsid proteins and purity by the lack of other contaminating bands.

158 AAV titer, defined as genome copies (GC)/mL was determined by qPCR. $1 \mu \mathrm{L}$ of

159 AAV sample was diluted into $16 \mu \mathrm{L} \mathrm{H}$ O, $1 \mu \mathrm{L}$ DNase I and $2 \mu \mathrm{L} 10 x$ DNase buffer (New

160 England Biolabs, Ipswich, MA, USA), and incubated for $30 \mathrm{~min}$ at $37^{\circ} \mathrm{C}$. The DNase I 
161 treated sample was serial diluted (1:5, 1:20, 1:100, 1:500 and 1:2500) and stored on ice

162 for qPCR. A standard curve, using a pAAV shuttle vector containing AAV2 ITRs,

163 ranging from $2 \times 10^{5}$ to $2 \times 10^{9}$ plasmid copies was constructed for calculating the AAV

164 titer. Three $5 \mu \mathrm{L}$ replicates of each sample dilution and standard curve concentration

165 were added to $15 \mu \mathrm{L}$ of SYBR ${ }^{\mathrm{TM}}$ Green PCR master mix (ThermoFisher) containing

$1660.67 \mu \mathrm{M}$ FWD and REV primers targeting the AAV2 ITRs. qPCR was performed on a

167 StepOnePlus ${ }^{\mathrm{TM}}$ system (ThermoFisher) using the following protocol: $3 \mathrm{~min}$ at $98^{\circ} \mathrm{C}$,

168 (melt at $98^{\circ} \mathrm{C}$ for $15 \mathrm{sec}$, anneal/extend at $60^{\circ} \mathrm{C}$ for $30 \mathrm{sec}$ ) x 39 cycles. Melt curves

169 were performed to verify a single amplification product. The $\mathrm{C}_{\mathrm{T}}$ value was defined as the

170 cycle number at which the amplification curve reached a $\Delta R n(R n-$ baseline, where $R n$

171 is the fluorescence of the reporter dye divided by the fluorescence of a passive

172 reference dye) threshold set at 0.1. A standard curve from the AAV2 plasmid standards

173 (concentration by $\mathrm{C}_{\mathrm{T}}$ ) was plotted, fit with a line and the concentration of each AAV

174 sample dilution was determined.

Surgery

Mice were anesthetized with isoflurane and stereotaxically injected with AAV

178 vectors into motor cortex $(100 \mathrm{~nL}$, coordinates relative to bregma in $\mathrm{mm}: \mathrm{A} / \mathrm{P}:+1.1$;

$179 \mathrm{M} / \mathrm{L}: \pm 1.7 ; \mathrm{D} / \mathrm{V}:-1.6)$ or DLS $(300 \mathrm{~nL}$, coordinates relative to bregma in mm: A/P: +

$180 \quad 0.75 ; \mathrm{M} / \mathrm{L}: \pm 2.5 ; \mathrm{D} / \mathrm{V}:-3.5)$ at a rate of $25-50 \mathrm{~nL} / \mathrm{min}$, using a 7000 series $0.5 \mu \mathrm{L}$

181 Hamilton syringe (Hamilton Company, Reno, NV, USA) and Pump 11 Elite Nanomite

182 (Harvard Apparatus, Holliston, MA, USA) syringe pump. Following surgery, mice were 
183 given an injection of Ketoprofen ( $5 \mathrm{mg} / \mathrm{kg}$, s.c.) and postoperative care was provided for

184 at least two days and until mice regained their preoperative weight.

\section{Slice Photometry}

Mice, 4-6 weeks after viral infusion, were deeply anesthetized with isoflurane,

188 decapitated and the brains extracted and placed in ice cold sucrose cutting solution (in

$189 \mathrm{mM}$ ): 194 sucrose, $30 \mathrm{NaCl}, 4.5 \mathrm{KCl}, 26 \mathrm{NaHCO}_{3}, 1.2 \mathrm{NaH}_{2} \mathrm{PO}_{4}, 10$ D-glucose, $1 \mathrm{MgCl}_{2}$

190 saturated with $5 \% \mathrm{CO}_{2} / 95 \% \mathrm{O}_{2}$. Coronal brain slices $(250 \mu \mathrm{m})$ were prepared with a

191 Leica VT1200S Vibratome (Leica Microsystems, Buffalo Grove, IL) and slices were

192 incubated at $32^{\circ} \mathrm{C}$ for 40-60 min in aCSF (in mM): $124 \mathrm{NaCl}, 4.5 \mathrm{KCl}, 26 \mathrm{NaHCO}_{3}, 1.2$

$193 \mathrm{NaH}_{2} \mathrm{PO}_{4}, 10 \mathrm{D}$-glucose, $1 \mathrm{MgCl}_{2}, 2 \mathrm{CaCl}_{2}$. After incubation at $32^{\circ} \mathrm{C}$, slices were held at

194 room temperature until transfer to a recording chamber.

196 upright epifluorescence microscope equipped with a 40x 0.8 NA water emersion

197 objective. Slices were placed in a recording chamber and superfused at $\sim 2 \mathrm{~mL} \mathrm{~min}^{-1}$

198 with aCSF warmed to $29-31^{\circ} \mathrm{C}$. A twisted bipolar polyimide-coated stainless-steel

199 stimulating electrode ( 200 $\mu \mathrm{m}$ tip separation) was placed in the DLS just medial to the

200 corpus callosum and slightly below the tissue surface in a region with visible

201 fluorescence. Using the 40x objective, focus was adjusted to just below the tissue

202 surface, at a similar height as the electrode tips. GRAB sensors were excited using

203 either a mercury HBO 100 lamp equipped with a Zeiss FluoArc variable intensity lamp

204 controller (Carl Zeiss Microcopy GmbH, Jena, Germany) and gated with a uniblitz 
205 shutter (Vincent Associates, Rochester, NY, USA), or a $470 \mathrm{~nm}$ light emitting diode

206 (LED, ThorLabs, Newton, NJ, USA). The Zeiss axiovert system was equipped with a

207 Zeiss 38 HE filter set (Ex. 470/40, FT 495, Em. 525/50), and the Olympus BX41 was

208 equipped with a FITC filter set (Ex. 475/28, FT 495, Em. 520/35). Excitation power was

209 measured at the sample plane using a microscope slide photodiode power sensor

210 (ThorLabs) and was $3.8 \mathrm{~mW}$ for the mercury HBO lamp and $<1.0 \mathrm{~mW}$ for the $470 \mathrm{~nm}$

211 LED. A $180 \mu \mathrm{m}^{2}$ aperture located in the light path between the microscope and

212 photomultiplier tube (PMT) was used so photons were collected from a region of interest

213 just medial to the stimulation electrode tips. Photons passing through the aperture were

214 directed to a PMT (Model D-104, Photon Technology International, Edison, NJ, USA)

215 with the cathode voltage set to 300-400 V. The PMT output was amplified (gain: 0.1

$216 \mu \mathrm{A} / \mathrm{V}$; time constant: $5 \mathrm{msec}$ ), filtered at $50 \mathrm{~Hz}$ and digitized at $250 \mathrm{~Hz}$ using a Digidata

217 1322A or a 1550B and Clampex software (Axon Instruments, Molecular Devices LLC,

218 Sunnyvale, CA, USA). For all experiments, GRAB sensor measurements were acquired

219 as discrete trials repeated every 3 minutes. For each trial, the light exposure period was

$220 \quad 35-45$ seconds to minimize sensor photobleaching, while capturing peak responses and

221 the majority of the decay phase (Figure 1C). To evoke an eCB or ACh transient, a burst

222 of electrical pulses (1.0-1.5 mA, 200-500 $\mu \mathrm{s})$ was delivered $5 \mathrm{~s}$ after initiating

223 fluorophore excitation. Transients were calculated as $\Delta \mathrm{F} / \mathrm{F}$ by averaging the PMT

224 voltage $(\mathrm{V})$ for a period of $1 \mathrm{~s}$ just prior to electrical stimulation $(\mathrm{F})$ and then calculating

225 V/F-1 for each digitized data sample.

226

227 Drugs 

stored at $-20^{\circ} \mathrm{C}$. Just prior to use, drugs were diluted to working concentrations in aCSF.

230 The final concentration of DMSO was $<0.1 \%$, a concentration that did not affect evoked

231 eCB transients. $\beta$-cyclodextrin (3.0 mg/50 mL, MilliporeSigma, Burlington, MA, USA)

232 was included as a carrier for AM251 and DO34 solutions. The compounds 2-AG, AEA,

233 AM251, URB597, JZL184, (-)-Quinpirole hydrochloride, VU 0255035, (RS)-3,5-

234 Dihyroxyphenylglycine (DHPG), 6,7-Dinitroquinoxaline-2,3-dione (DNQX) disodium salt,

235 DL-2-Amino-5-phosphonopentanoic acid (DL-AP5), JNJ16259685 and 2-Methyl-6-

236 (phenylethynyl)pyridine (MPEP) hydrochloride were purchased from Tocris (Minneapolis

237 MN, USA). ( \pm )-Sulpiride was purchased from MilliporeSigma. DO34 was purchased

238 from Aobious (Gloucester, MA, USA). VU 0486846 was generously provided by Dr.

239 Jeffery Conn (Vanderbilt University, Nashville, TN, USA).

241 Data analysis

Slice photometry raw data were collected and analyzed using the plamp ${ }^{\mathrm{TM}}$

243 software suit (v9.2 and v10; Molecular Devices, San Jose, CA, USA). Photometry

244 sweeps were exported to Microsoft Excel (v16.3; Redmond, WA, USA) to calculate

245 normalized $\Delta F / F$ traces, peak $\Delta F / F$ values, eCB mobilization time and $\%$ baseline

246 timecourse data. Rise $\mathrm{t}_{1 / 2}$ was calculated in Graphpad Prism (v8.3; San Diego, CA,

247 USA) by fitting the rising phase of the eCB transient with an asymmetrical logistic curve.

248 Statistical analysis and graph rendering were performed using Graphpad Prism.

249 Baseline normalized timecourse data were analyzed using one sample t-tests, 1-way 
250 rmANOVAs followed by Tukey's multiple comparisons test or by 2-way rmANOVAs

251 followed by Sidak's multiple comparisons test. For t-tests and 1-way rmANOVA

252 analysis, baseline was the average peak $\Delta F / F$ of 5 predrug sweeps (for 1-way ANOVA

253 only), drug condition was the average peak $\Delta F / F$ of the last two data points of the drug

254 application period (except for (RS)-DHPG experiments where only the sweep with the

255 highest peak $\Delta F / F$ was used) and washout/antagonist wash (for 1-way ANOVA only)

256 was the average of the last two data points during that period. Data are plotted as mean

$257 \pm$ standard error of the mean.

259 Results

260 The novel genetically encoded biosensor, GRABeCB2.0, detects eCB transients induced

261 by electrical stimulation in the DLS.

262 To study eCB mobilization in the DLS, we used an ex vivo brain slice photometry

263 technique similar to published reports using GCaMP calcium sensors (Kupferschmidt

264 and Lovinger, 2015; Sgobio et al., 2014). AAV2/9.hSyn.GRABecB2.0 and

265 AAV2/9.hSyn.GRABесвмuт vectors were infused into motor cortex (M1/M2) of wildtype

266 C57BL/6J mice and 4-6 weeks later, eCB transients were measured at corticostriatal

267 afferents in the DLS (Figure 1A-C).

268 Fluorescent transients from GRAB

269 the amplitude of these transients increased with higher stimulation frequencies up to

$270100 \mathrm{~Hz}$ ( $\mathrm{n}=3$, Figure 1D). To confirm the specificity of the fluorescent transients, slices

271 were preincubated in AM251 (10 $\mu \mathrm{M})$ for $\sim 1 \mathrm{hr}$ before performing photometry 
272 experiments. In these slices, fluorescent transients were not detected in response to

273 train stimulation up to $100 \mathrm{~Hz}(n=3)$. Additionally, evoked eCB transients could not be

274 measured with the GRAB ${ }_{\text {eCBMUt sensor }(~}=6$, Figure 1E), which contains the mutation

275 F177A that greatly reduces 2-AG and AEA affinity, demonstrating that the fluorescent

276 transients measured with $\mathrm{GRAB}_{\mathrm{eCB} 2.0}$ are dependent on agonist occupancy of the

277 orthosteric binding site of CB1R contained within the sensor.

278 In the cerebellum, brief stimulation of parallel fibers (i.e. 5 or 10 pulses at $50 \mathrm{~Hz}$ )

279 triggers eCB mobilization and short-term depression (Brown et al., 2003; Maejima et al.,

280 2001). We tested whether similar stimulation protocols are sufficient to activate eCB

281 production in the DLS. Indeed, eCB transients could be measured in response to brief

282 trains of electrical stimulation (Figure 2). Paired-pulse stimulation evoked small, but

283 measurable, eCB transients that increased slightly in amplitude at higher frequencies.

284 Trains of 5 or 10 pulses evoked larger transients that were augmented by increasing the

285 stimulation frequency up to $100 \mathrm{~Hz}$ (Figure 2A\&B). The eCB transients developed over

286 several seconds measured from the start of train stimulation, with a mean $\mathrm{t}_{1 / 2}$ rise time

287 of $1.4 \pm 0.03$ seconds regardless of stimulation frequency (Figure 2C). The eCB decay

288 phase was well described by a single exponential function and was similar across all

289 stimulation pulse numbers and frequencies with a mean tau of $13.7 \pm 0.3$ seconds

290 (Figure 2D).

291 There was a notable delay between the start of synaptic stimulation and any

292 measurable increase in $\mathrm{GRAB}_{\mathrm{eCB}}$.o fluorescence, which we refer to as the eCB

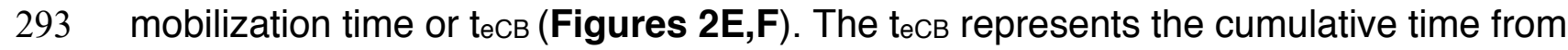


294 the start of synaptic stimulation and recruitment of postsynaptic eCB production

295 machinery, to retrograde eCB transit and binding to the GRAB $\mathrm{eCB}_{2.0}$ sensor. Thus, this

296 measurement may correlate with the minimum time required for eCB-dependent

297 presynaptic inhibition (Heinbockel et al., 2005). The tecв was measured from the start of

298 train stimulation to the time at which the presynaptic $\mathrm{GRAB}_{\mathrm{eCB} 2.0}$ fluorescence reached a

299 threshold set at $3 x$ rms of the baseline fluorescence and was $0.301 \pm 0.01$ seconds

300 regardless of stimulation frequency (Figure 2F).

2-AG is the predominant eCB mobilized by brief synaptic stimulation in the DLS.

Previous studies have shown that both 2-AG and AEA can be generated by

synaptic stimulation in the striatum, but which eCB predominates depends on the

specific experimental induction protocol used (Lerner and Kreitzer, 2012). To investigate

whether 2-AG and/or AEA are mobilized by brief synaptic stimulation, we measured the

$69.9 \%$ of baseline, $p<0.05, n=5$ ), consistent with inhibition of $2-A G$ degradation.

311 Additionally, the basal fluorescence, $F$, increased ( $155.3 \pm 21.8 \%$ of baseline, $n=6)$,

312 indicating that MAGL inhibition generates a 2-AG tone in the DLS. In contrast, bath

313 application of URB597 $(1 \mu \mathrm{M})$ did not significantly prolong the decay rate of the evoked

314 eCB transient (Figure 3B, $134.6 \pm 14.8 \%$ of baseline, $p>0.05, n=5$ ), or change the

315 basal fluorescence $(108.1 \pm 4.4 \%$ of baseline, $p>0.05, n=5)$. To confirm that the eCB 
316 transients evoked by brief synaptic stimulation were 2-AG, we tested whether

317 diacylglycerol lipase (DAGL) inhibition would inhibit the transients evoked by 5 pulse

318 bursts at $20 \mathrm{~Hz}$ (Figure 3C). Indeed, preincubating slices in the DAGL inhibitor, DO34

$319(1 \mu \mathrm{M})$, for $\sim 1 \mathrm{hr}$ significantly reduced the peak amplitude of the eCB transient over a 320 range of stimulation intensities $(p<0.0001, n=5 / 6)$.

Metabotropic and ionotropic glutamate receptors contribute to 2-AG mobilization

\section{3}

324

325

326

327

328

329

330

331

332

333

334

335

336

337 following brief synaptic stimulation

Group I mGluRs induce eCB-dependent plasticity at many synapses in the brain, including the corticostriatal synapse (Calabresi et al., 1992; Gubellini et al., 2001;

Kreitzer and Malenka, 2005; Sung et al., 2001). In the DLS, mGlu1 and mGlu5 are implicated in HFS-LTD and exogenous activation mGlu1/5 induces eCB-LTD (Kreitzer and Malenka, 2005). Therefore, we tested whether 2-AG production evoked by brief synaptic stimulation (5p 20Hz) involved recruitment of mGlu5 and/or mGlu1 (Figure 4). Bath application of the mGlu5 negative allosteric modulator (NAM) MPEP (10 $\mu \mathrm{M})$ reduced the amplitude of the $2-A G$ transient to $79.8 \pm 6.0 \%$ of baseline (Figure $4 \mathrm{~A}, \mathrm{p}<$ $0.01, \mathrm{n}=5$ ) and bath application of the mGlu1 NAM, JNJ16259685 (JNJ'685, 1 $\mu \mathrm{M})$, reduced the amplitude of the $2-A G$ transient to $83.9 \pm 6.1 \%$ of baseline (Figure $4 B, p<$ $0.05, \mathrm{n}=5$ ). Given the role of mGlu5 and mGlu1 in evoked 2-AG transients, we tested whether activation of mGlu1/5 with an exogenous agonist could enhance the 2-AG transient. Bath application of (RS)-DHPG $(100 \mu \mathrm{M})$ caused a biphasic change in the amplitude of the evoked 2-AG transient (Figure 4C). The maximum augmentation was 
$173.3 \pm 7.4 \%$ of baseline, which occurred during the first evoked transient following

(RS)-DHPG application ( $n=5, p<0.0001)$. This modulation subsequently decayed over

340 time with the 2-AG amplitude plateauing at $75.3 \pm 4.1 \%$ of baseline $(n=5, p<0.05)$.

341 The baseline fluorescence intensity ( $F$, as defined in Figure $1 \mathrm{C})$ was not changed by

342 (RS)-DHPG (data not shown). Collectively, these results show that group I mGluRs can

343 couple to 2-AG generation mechanisms as previously demonstrated in the DLS using

344 electrophysiology approaches, and that mGlu5 and mGlu1 activation contributes to 2-

345 AG generation following brief synaptic stimulation.

Postsynaptic depolarization and activation of voltage gated calcium channels is

347 required for many forms of eCB dependent STD and LTD. One presumed source of

348 depolarization for synaptically-driven eCB generation is ionotropic AMPA receptors

349 (AMPARs) (Brown et al., 2003). However, few reports directly demonstrate the

350 involvement of AMPARs in eCB production because AMPAR mediated EPSC/EPSP

351 amplitude is a primary measurement for studying eCB physiology at excitatory

352 synapses. With the ability to measure eCB generation directly using GRABeCB2.0, we

353 tested the hypothesis that AMPARs are a primary voltage source for synaptically driven

354 2-AG production in the DLS (Figure 4D). Bath application of the AMPAR antagonist,

355 DNQX $(10 \mu \mathrm{M})$, rapidly decreased the amplitude of evoked $(5 \mathrm{p} 20 \mathrm{~Hz}) 2-\mathrm{AG}$ transients to

$35633.1 \pm 8.1 \%$ of the baseline amplitude $(n=5, p<0.0001)$, which reversed back towards

357 baseline over a 30 min washout period $(81.1 \pm 3.4 \%$ baseline, $p<0.001$ compared to

358 DNXQ). We next tested if AMPAR-dependent depolarization engaged L-type calcium

359 channels leading to 2-AG generation. Bath application of the LTCC blocker, nifedipine 
$360(10 \mu \mathrm{M})$, did not reduce the amplitude of the evoked 2-AG transient (data not show),

361 suggesting another voltage sensitive calcium channel/receptor may be responsible for

362 triggering 2-AG generation. One possibility is the NMDA receptor (NMDAR). Indeed,

363 bath application of the NMDAR antagonist, DL-AP5 $(50 \mu \mathrm{M})$, resulted in a rapid

364 reduction in the evoked 2-AG transient to $25.7 \%$ of baseline (Figure 4E, $n=4, p<$

365 0.0001), which reversed back towards baseline over a 30 min washout period (65.8 \pm

$3667.9 \%$ baseline, $p<0.05$ compared to DL-APV).

Muscarinic M1 receptors contribute to synaptically driven 2-AG mobilization

DSI (Narushima et al., 2007) and are required for eCB mediated spike timing-dependent

371 plasticity (Fino et al., 2010). On the other hand, M1Rs inhibit HFS-LTD by inhibiting L-

372 type calcium channels (Wang et al., 2006). Given these opposing roles in modulating

373 eCB short-term and long-term plasticity, we investigated the role of M1Rs on 2-AG

374 generation following brief synaptic stimulation $(5 p 20 \mathrm{~Hz})$. Bath application of the M1R

375 antagonist VU 0255035 (VU'035, $1 \mu \mathrm{M}$ ) reduced the amplitude of the evoked 2-AG

376 transient to $36.1 \pm 4.3 \%$ of the baseline $(n=3, p<0.001)$, which did not washout

377 (Figure 5A). To further investigate the role of M1Rs on 2-AG production, we bath

378 applied the M1R positive allosteric modulator (PAM), VU 0486846 (VU'846, $10 \mu M$ ),

379 which increased the 2-AG peak amplitude to $274.4 \pm 40.6 \%$ of baseline $(n=5, p<0.01$,

380 Figure 5B). The baseline fluorescence intensity (F) was not changed by VU'035 or

381 VU'846 (data not shown), suggesting that tonic acetylcholine (ACh) release from 
382 cholinergic interneurons (CINs) does not generate an eCB tone through M1R

383 stimulation.

M1R and Group I mGluRs facilitate 2-AG production by distinct mechanisms

Both M1R and AMPAR antagonists robustly inhibited (>60\%) 2-AG production,

387 suggesting these receptors converge on a common signaling mechanism. To

388 investigate this possibility, we measured the effect of the M1R PAM, VU'846, on 2-AG

389 generation while blocking AMPA receptors (Figure 6A). First, DNQX (10 $\mu \mathrm{M})$ was bath

390 applied, which reduced the $2-A G$ transient to $34.4 \pm 2.6 \%$ of baseline $(n=3, p<$

391 0.0001), a similar magnitude of inhibition as observed in the previous experiment with

392 this antagonist. After the inhibitory effect of DNQX plateaued, VU'846 (10 $\mu \mathrm{M})$ was co-

393 applied with DNQX. DNQX completely occluded the effect of VU'846 on 2-AG

394 production ( $p>0.05$ compared to DNQX alone), suggesting that M1Rs and AMPARs

395 share a common signaling pathway leading to 2-AG production. It is possible that

396 AMPARs located on CINs are required for driving ACh release rather than directly

397 involved in eCB production in MSNs. To test this hypothesis, we expressed the

398 genetically encoded ACh sensor, GRABACh3.0 (Jing et al., 2020) in the DLS and

399 measured ACh transients evoked by train stimulation (5 pulses at $20 \mathrm{~Hz}$ ). Bath

400 application of DNQX $(10 \mu \mathrm{M})$, did not change the amplitude of the evoked ACh

401 transients (data not shown), demonstrating that the role of AMPA receptors in 2-AG

402 production is not related to ACh release. Another possibility is that AMPA receptors

403 depolarize the postsynaptic cell allowing NMDA receptor activation and subsequent 
$404 \mathrm{Ca}^{2+}$ influx that feeds into M1R signaling mechanisms. If this hypothesis is correct, then

405 inhibition of NMDA receptors should also occlude the effect of VU'846 on 2-AG

406 production. Bath application of DL-AP5 $(50 \mu \mathrm{M})$ reduced the amplitude of the 2-AG

407 transient to $28.6 \% \pm 2.3 \%$ of baseline $(n=4, p<0.0001)$, similar to the previous

408 experiment with this antagonist, and occluded the effect of VU'846 on 2-AG production

409 ( $p>0.05$ compared to DL-AP5 alone, Figure 6B).

$410 \quad$ Given that M1R and mGlu1/5 both couple to $\mathrm{Ga}_{\mathrm{q} / 11}$ heterotrimeric g-proteins, we

411 investigated whether (RS)-DHPG enhancement of 2-AG production was also dependent

412 of AMPAR activation. Again, bath application of DNQX (10 $\mu \mathrm{M})$ reduced the 2-AG

413 transient to $30.3 \pm 6.8 \%$ of baseline $(n=3, p<0.01)$, however co-application of DNQX

414 did not block (RS)-DHPG enhancement of 2-AG production ( $p<0.05$ compared to

415 DNQX, Figure 6C).

416

417 Dopamine D2 receptors on cholinergic interneurons inhibit 2-AG release.

418 Activation of dopamine D2Rs is required for the expression of HFS-LTD in the

419 dorsal striatum. The mechanism by which D2Rs participate in HFS-LTD has been

420 debated in the literature, however it's clear that D2Rs on cholinergic interneurons are

421 required for inhibiting ACh release and M1R activation (Augustin et al., 2018; Wang et

422 al., 2006). In contrast to HFS-LTD, we found that brief synaptic stimulation requires

423 M1R activation for 2-AG generation. Thus, we hypothesized that D2Rs would inhibit,

424 rather than promote, 2-AG generation following brief synaptic stimulation $(5 p 20 \mathrm{~Hz})$.

425 Indeed, bath application of the D2R agonist quinpirole $(1 \mu \mathrm{M})$, reduced the amplitude of 
426 evoked 2-AG transient to $61.1 \pm 4.2 \%$ of baseline $(n=5, p<0.01$, Figure 7A). The

427 specificity of this action of quinpirole for D2Rs was confirmed by co-application of the

428 D2R antagonist, sulpiride $(10 \mu \mathrm{M})$, which reversed the effect of quinpirole and

429 subsequently increased the amplitude of the evoke $2-A G$ transient to $131.4 \pm 11.5 \%$ of

430 the initial baseline amplitude $(p<0.05)$. The rebound effect of sulpiride suggests that 20

$431 \mathrm{~Hz}$ electrical stimulation elicits dopamine release from midbrain dopamine (DA) fibers to

432 limit 2-AG generation by acting on D2Rs.

433 Our results showing that M1R inhibition or D2R activation suppresses 2-AG

434 generation is consistent with the hypothesis that D2Rs on CINs are the target of

435 quinpirole and endogenously released DA. To support of this hypothesis, we expressed

436 the ACh sensor, GRABACh3.0, in the DLS to examine the effect of D2R activation of ACh

437 release (Figure 7B). ACh release evoked by 5 pulse $20 \mathrm{~Hz}$ train stimulation was

438 inhibited by bath application of quinpirole $(1 \mu \mathrm{M}, \mathrm{n}=4,39.1 \%$ of baseline, $\mathrm{p}<0.05)$,

439 which was reversed by the addition of sulpiride $(10 \mu \mathrm{M}, 101.5 \%$ of baseline, $\mathrm{p}>0.05$

440 compared to baseline).

441 To further confirm the role of CIN D2Rs on 2-AG production, we bred D2R-flox

442 mice with ChAT-IRES-Cre mice to conditionally knockout D2Rs from CINs (CIN-

443 Drd2KO) and measured the effect of quinpirole and sulpiride on 2-AG production

444 (Figure 7C). Qualitatively, the 2-AG transients evoked in slices from CIN-Drd2KO mice

445 were indistinguishable from 2-AG transients evoked in slices from wildtype C57BL/6J or

$446 \mathrm{D} 2 \mathrm{R}^{\text {flox/flox }}$ mice. The inhibitory effect of quinpirole $(1 \mu \mathrm{M})$ on 2-AG production was lost in

447 slices from CIN-Drd2KO mice ( $n=4 / 5$ per group, $p<0.001$ compared to D2R ${ }^{\text {flox/flox }}$ ). 
448 Additionally, sulpiride $(10 \mu \mathrm{M})$ did not enhance 2-AG production in slices from CIN-

449 Drd2KO mice ( $p<0.05$ compared to $\left.\mathrm{D} 2 \mathrm{R}^{\text {flox/flox }}\right)$. These results confirm that stimulation

450 of D2Rs on cholinergic interneurons, by either exogenous agonist application or

451 endogenously release DA, inhibit 2-AG generation induced by brief synaptic stimulation.

\section{Discussion}

In this report, we used the novel genetically encoded intensity-based biosensor,

$455 \mathrm{GRAB}_{\mathrm{eCB}} .0$, in combination with brain slice photometry to study eCB signaling dynamics

456 in the DLS. This approach offers several advantages over traditional

457 electrophysiological techniques to studying eCB physiology. For example, we were able

458 to make direct measurements of eCB mobilization at corticostriatal afferents, the

459 primary site of action for eCBs, and were able study eCB mobilization mechanisms

460 without perturbing the postsynaptic neurons. In addition, we examine the roles of

461 ionotropic receptors more thoroughly than in past studies that relied on the function of

462 these receptors as the readout for eCB actions. Using this approach, we show that brief

463 bouts of synaptic stimulation induce long lasting 2-AG transients, which are dependent

464 on convergent signals from AMPARs and $\mathrm{Ga}_{\mathrm{q} / 11}$ coupled GPCRs (Figure 8). Our data

465 indicate that mGlu1/5 and M1Rs trigger 2-AG mobilization though distinct mechanisms

466 with divergent dependence on AMPAR activation and subsequent rises in intracellular

$467 \mathrm{Ca}^{2+}$ concentration through NMDARs. Furthermore, D2Rs located on CINs inhibit

468 evoked 2-AG transients by limiting ACh release and M1R stimulation. Collectively, the 
469 present study provides new insights on circuit and cellular mechanisms controlling 2-AG

470 mobilization in the DLS.

471 We measured eCB mobilization kinetics following brief, physiologically relevant,

472 synaptic stimulation. eCB transients could be evoked by paired-pulse stimulation, but

473 these transients were small and variable. Increasing the number of stimuli to 5 or 10

474 pulses produced progressively larger transients that were sensitive to stimulation

475 frequency up to $100 \mathrm{~Hz}$. Interestingly, this dependence on stimulus number and

476 frequency closely parallels the stimulation dependence of eCB-mediated inhibition of

477 presynaptic $\mathrm{Ca}^{2+}$ transients and STD induced by synaptic stimulation in the cerebellum

478 (Brown et al., 2003; Maejima et al., 2001), suggesting that the neural activity rules

479 supporting eCB mobilization may be generalized across brain regions. The synaptically-

480 evoked eCB transients were slow compared to the signaling dynamics of many other

481 neurotransmitter systems. The transients took several seconds to reach peak

482 amplitudes and decayed over the course of tens of seconds; kinetics consistent with

483 reported durations of eCB-dependent STD. In contrast, transients evoked by single or

484 multiple stimuli and measured with GPCR-based ACh and DA sensors peak within less

485 than a second and persist for only a few seconds after stimulus cessation (Jing et al.,

486 2020; Patriarchi et al., 2018; Sun et al., 2018). The minimum time from the onset of

487 synaptic stimulation to detecting eCBs at corticostriatal afferents, which we have

488 defined as the eCB mobilization time ( $\mathrm{teCB}_{\mathrm{e}}$ ), was $\sim 300 \mathrm{~ms}$ regardless of stimulation

489 protocol. In our experiments, tесв represents the cumulative time for glutamate and ACh

490 release, post synaptic eCB generation, retrograde transit to corticostriatal membranes, 


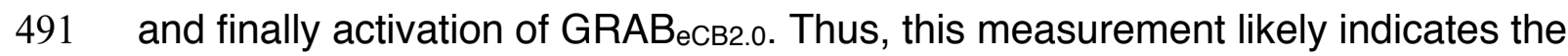

492 minimum time required for eCB-dependent presynaptic inhibition following synaptic

493 stimulation. Consistent with this notion, our measurements of tecB are similar to

494 estimates of the minimum time required for DSI expression (tDsI) in CA1 pyramidal cells 495 (Heinbockel et al., 2005). eCB transients evoked by brief synaptic stimulation $(5 p 20 \mathrm{~Hz})$ were sensitive to

497 MAGL inhibition, indicating that 2-AG is mobilized under these conditions. Specifically, 498 when $\mathrm{GRAB}_{\mathrm{eC} 2.0}$ was expressed in corticostriatal afferents, MAGL inhibition prolonged 499 the decay component of the eCB transient and increased basal fluorescence, consistent 500 with the generation of a 2-AG tone. Furthermore, DAGL inhibition decreased the peak 501 amplitude of the of eCB transient by $75-80 \%$, suggesting that $2-A G$ is the primary eCB 502 evoked by our stimulation protocol. On the other hand, FAAH inhibition, did not 503 significantly affect on eCB transients evoked using the same stimulation protocol, 504 suggesting that AEA is not efficiently mobilized under these conditions. 2-AG transients evoked by brief synaptic stimulation were dependent on

506 ionotropic and metabotropic glutamate receptors. Inhibition of mGlu5 or mGlu1

507 decreased the 2-AG transient by 15-20\%,. Furthermore, the mGlu1/5 agonist, DHPG, 508 increased the $2-\mathrm{AG}$ transient by $175 \%$, indicating that the $5 \mathrm{p} 20 \mathrm{~Hz}$ train stimulation

509 protocol does not saturate mGlu1/5 dependent eCB mobilization pathways.

510 Interestingly, the effect of DHPG was bi-phasic as the initial potentiation of 2-AG

511 generation gradually declined and eventually lead to depression. There are two

512 explanations for these results. First, DHPG enhancement of 2-AG signaling may 
513 activate a negative feedback mechanism by which the enhanced 2-AG production leads

514 to depression of corticostriatal transmission and disengagement of AMPAR activation,

515 which our data show is a critical component of 2-AG generation. Alternatively, it is

516 possible that prolonged application of DHPG leads to receptor desensitization

517 effectively reducing mGluR signaling. Supporting this mechanism, the delayed DHPG

518 depression of 2-AG production was similar in magnitude to the inhibition observed with

519 mGluR antagonism. We favor this latter mechanism because VU'846, an M1R PAM that

520 also augments evoked 2-AG mobilization, did not have the same biphasic effect.

521 However, we cannot rule out potential differences between mGluR and M1R signaling

522 that may contribute to differences in eCB production.

We found that blocking AMPA receptors decreased the 2-AG transient by $67 \%$

524 indicating that these receptors are indispensable for robust 2-AG generation evoked by

525 brief synaptic stimulation. A previous study was able to show the involvement of

526 AMPARs in synaptically generated eCB-STD in the cerebellum by optical

527 measurements of presynaptic $\mathrm{Ca}^{2+}$ transients, however, AMPARs were only a minor

528 component (Brown et al., 2003). Our experiments suggest that AMPAR activation

529 depolarizes the postsynaptic membrane allowing NMDAR activation and a subsequent

530 rise in intracellular $\mathrm{Ca}^{2+}$, as inhibition of NMDARs decreased the $2-\mathrm{AG}$ transient by $74 \%$.

$531 \quad$ Muscarinic M1Rs modulate STD and LTD in several brain regions. In the DLS,

532 M1Rs are required for LTD induced by STDP protocols (Fino et al., 2010), but suppress

533 LTD induced by HFS (Wang et al., 2006). Furthermore, M1Rs enhance DSI in MSNs

534 and can promote DSE through synergistic actions with mGlu5 (Narushima et al., 2007; 
535 Uchigashima et al., 2007). Thus, depending on the eCB induction protocol, M1Rs can

536 either promote or suppress eCB-dependent plasticity. In the current study, 2-AG

537 transients were robustly inhibited by M1R antagonists and augmented by a M1R PAM,

538 indicating that $\mathrm{ACh}$ released from $\mathrm{CINs}$ provides a major contribution to 2-AG

539 production induced by brief trains of synaptic stimulation. Our data show that blocking

540 M1Rs, AMPARs or NMDARs inhibited the eCB transient by $60-75 \%$, suggesting these

541 receptors converge on a common signaling pathway leading to eCB production. Indeed,

542 inhibiting AMPARs or NMDARs blocked 2-AG enhancement by the M1R PAM. Our data

543 showing that AMPAR antagonists don't inhibit evoked ACh release, measured with

544 GRAB $_{A C h 3.0,}$ argue against a role for ionotropic glutamate receptors on CINs in the ACh

545 release that drives M1R activation. Alternatively, activation of AMPARs and NMDARs

546 on MSNs can lead to rises in intracellular $\mathrm{Ca}^{2+}$ that may converge with $\mathrm{Ga}_{\mathrm{q} / 11}$ signaling

547 mechanisms, leading to 2-AG generation.

548 In contrast to M1Rs, the effect of mGlu1/5 stimulation is independent of AMPAR

549 activation as DHPG still enhanced the eCB transient in the presence of AMPAR

550 antagonists. These results suggest that in the context of brief synaptic stimulation,

551 M1Rs generate 2-AG though a $\mathrm{Ca}^{2+}$-assisted receptor-driven eCB release $\left(\mathrm{Ca}^{2+}\right.$

552 assisted RER) mechanism, while mGlu1/5s may signal by a $\mathrm{Ca}^{2+}$ independent

553 receptor-driven eCB release (RER) mechanism. Our findings suggesting that mGlu1/5

554 signals though an RER mechanism is consistent with reports in the hippocampus and

555 cerebellum (Chevaleyre and Castillo, 2003; Kim et al., 2002; Maejima et al., 2001). In

556 the DLS, however, DHPG-induced LTD is dependent on postsynaptic depolarization 
557 and L-type calcium channels (Kreitzer and Malenka, 2005). Although these results are

558 in contrast to our observations, in the striatum mGlu1/5 can trigger eCB-LTD

559 through $\mathrm{Ca}^{2+-}$ dependent and $\mathrm{Ca}^{2+-i n d e p e n d e n t ~ m e c h a n i s m s ~(L e r n e r ~ a n d ~ K r e i t z e r, ~}$

560 2012). The study by Lerner and Kreitzer showed LTD requiring 2-AG mobilization is

$561 \mathrm{Ca}^{2+}$ independent, consistent with our findings, while LTD requiring AEA mobilization is

$562 \mathrm{Ca}^{2+}$ dependent. Indeed, $\mathrm{Ca}^{2+}$ dependent AEA mobilization underling HFS-LTD

563 induction in the DLS is in agreement with previous reports (Ade and Lovinger, 2007;

564 Calabresi et al., 1994; Choi and Lovinger, 1997). Thus, the $\mathrm{Ca}^{2+}$ dependence of

565 mGlu1/5 induced eCB mobilization might depend on whether the cellular context favors

566 2-AG or AEA production.

567 Activation of D2Rs by exogenous application of quinpirole or by endogenous DA

568 release suppressed the amplitude of evoked 2-AG transients. This result was somewhat

569 surprising because D2R activation is required for eCB-dependent LTD in the DLS

570 (Calabresi et al., 1992) and quinpirole inhibits evoked EPSCs in MSNs in a frequency

571 and CB1R-dependent manner (Wang et al., 2012; Yin and Lovinger, 2006). In the

572 context of HFS-LTD, D2Rs expressed on CINs promote eCB signaling by limiting ACh

573 release and subsequent activation of M1Rs located on MSNs (Augustin et al., 2018;

574 Wang et al., 2006), which is opposite to the mechanism uncovered in our study. These

575 independent findings, although seemingly contradictory, suggest that M1Rs can either

576 inhibit or augment eCB production, depending on the level of neural activity, and D2Rs

577 regulate the magnitude of eCB modulation by M1Rs regardless of the sign. Importantly,

578 2-AG is the predominate eCB mobilized following brief synaptic stimulation in our study, 
579 while evidence suggests that AEA is the predominate eCB underlying HFS-LTD (Ade

580 and Lovinger, 2007; Lerner and Kreitzer, 2012). Thus, it is conceivable that the D2R-

581 ACh-M1R signaling mechanism differently regulates 2-AG and AEA production. In

582 support of this hypothesis, activation of D2-like DA receptors increases AEA levels in

583 the dorsal striatum and limbic forebrain, while D2R inhibition increases 2-AG content in

584 limbic forebrain (Giuffrida et al., 1999; Patel et al., 2003). At the molecular level, M1Rs

585 couple to $\mathrm{Ga}_{\mathrm{q} / 11}$ so 2-AG production may well occur through the canonical PLC and

586 DAGL pathway. On the other hand, M1Rs can inhibit LTCCs (Howe and Surmeier,

587 1995; Perez-Burgos et al., 2008), which is the mechanism responsible for suppressing

588 eCB-LTD and presumably AEA production. Interestingly, in our study, 2-AG production

589 required NMDARs, rather than LTCCs, thus different sources of $\mathrm{Ca}^{2+}$ influx may

590 contribute to differential regulation of eCBs by M1Rs.

591 In conclusion, we implemented the novel genetically encoded biosensor,

592 GRAB $\mathrm{eCB}_{2.0}$, to uncover unrecognized signaling mechanisms underlying 2-AG

593 production in the DLS. We confirmed the involvement of ionotropic receptors in eCB

594 production, which has long been hypothesized, but largely intractable to traditional

595 electrophysiological techniques. In addition, we made direct measurements of eCB

596 production on physiological time scales, which has not been possible previously.

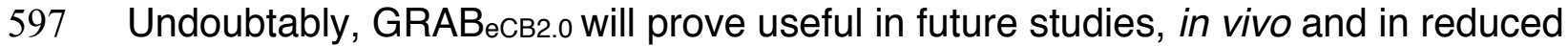

598 preparations, to gain further insight into eCB signaling under physiological and

599 pathological conditions (Dong et al., 2020).

600 


\section{Author contributions}

602 D.J.L and D.M.L designed the experiments. D.J.L performed the experiments and 603 analyzed the data. A.D. K.H. and Y.L. provided the $\mathrm{GRAB}_{\mathrm{eCB} 2.0}$ and $\mathrm{GRAB}_{\mathrm{ACh} 3.0}$ sensor

604 constructs. H.L.P contributed to sensor validation experiments. D.J.L. and D.M.L wrote 605 the manuscript with input from the other authors.

\section{Funding}

608 This work was supported by the National Institutes of Health, National Institute on

609 Alcohol Abuse and Alcoholism, Division of Intramural Clinical and Biological Research 610 (ZIA AA000416).

\section{Acknowledgements}

613 We thank Guoxiang Luo for genotyping assistance. We are grateful to the NIAAA

614 animal care staff for their excellent animal husbandry and veterinary care.

\section{Figure legends}

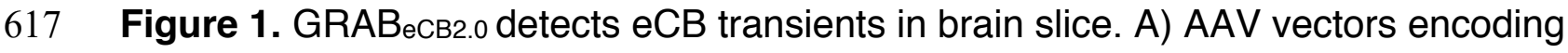

$618 \mathrm{GRAB}_{\text {eCB2.o }}$ were infused into motor cortex (M1/M2) and fluorescence from corticostriatal

619 afferents was measured in the DLS. B) Representative fluorescent micrographs of

$620 \mathrm{GRAB}_{\mathrm{eCB}} .0$ expression at the injection site in M1/M2 and in corticostriatal afferents in

621 the DLS. C) Top: raw photometric recording labeled to indicate $F$ and $\Delta F$

622 measurements, epifluorescence exposure time and timing of electrical stimulation. 
623 Bottom: normalized eCB transient evoked by a train of electrical stimuli. D) GRAB eCB2.0

624 fluorescent transients evoked by 1 s train stimulation at the indicated frequency were

625 blocked by AM251 ( $n=3$ slices/group, 2-way RM ANOVA, Drug: $F_{(1,8)}=113.8, p<$

$626 \quad 0.0001$; Frequency: $F_{(3,8)}=5.9, p<0.05$; Interaction: $\left.\left.F_{(3,8)}=2.6, p>0.05\right) . E\right)$

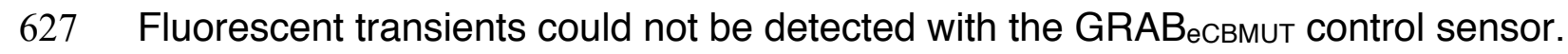

Figure 2. Evoked eCB transients are modulated by stimulation frequency and duration.

A) Representative traces of eCB transients evoked by brief trains of synaptic

631 stimulation. B) The amplitude of the eCB transient increased as a function train pulse

632 number and stimulation frequency. C) The eCB transient rise time, defined at the time to

633 reach $50 \%$ of the transient peak amplitude, were similar across all stimulation protocols.

634 D) Decay kinetics were similar across all stimulation protocols. E) Schematic illustrating

635 the calculation of eCB mobilization time (

636 stimulation protocols.

638 Figure 3. 2-AG is the main eCB mobilized by brief synaptic stimulation. A) Bath

639 application of MAGL inhibitor, JZL184, for 75 min prolonged the decay of the evoked

640 eCB transient $\left(n=5\right.$ slices, 1 sample t-test, $\left.t_{(4)}=3.164, p<0.05\right)$ and increased the

641 basal fluorescence $\left(n=6\right.$ slices, 1 sample t-test, $\left.t_{(5)}=2.535, p=0.052\right)$. B) Bath

642 application of the FAAH inhibitor, URB597, for 75 min had no effect on the decay of the

643 evoked eCB transient $\left(n=5\right.$ slices, 1 sample t-test, $\left.t_{(4)}=2.341, p>0.05\right)$ or basal

644 fluorescence $\left(n=5\right.$ slices, 1 sample t-test, $\left.t_{(4)}=1.858, p>0.05\right) . C$ ) The amplitude of 
645 evoked eCB transients was reduced by preincubating slices in the DAGL inhibitor,

646 DO34 ( $n=5 / 6$ slices, 2-way RM-ANOVA, Drug: $F_{(1,9)}=48.31, p<0.0001$; Amplitude:

$647 F_{(6,54)}=76.11, p<0.0001$; Interaction: $\left.F_{(6,54)}=34.23, p<0.0001\right)$.

Figure 4. Synaptically evoked 2-AG transients are dependent on metabotropic and

650 ionotropic glutamate receptors. A) The mGlu5 NAM, MPEP, decreased the peak

651 amplitude of the 2-AG transient $\left(n=5\right.$ slices, 1 -way RM ANOVA, Drug: $F_{(2,8)}=12.14, p$

$652<0.01)$. B) The mGlu1 NAM, JNJ'685, decreased the peak amplitude of the 2-AG

653 transient ( $n=5$ slices, 1 -way RM ANOVA, Drug: $\left.F_{(2,8)}=5.531, p<0.05\right)$. C) The

654 mGlu1/5 agonist, (RS)-DHPG, had a biphasic effect on 2-AG production ( $\mathrm{n}=5$ slices, 1-

655 way RM ANOVA, Drug: $\left.F_{(2,8)}=97.33, p<0.0001\right)$. D) The AMPAR antagonist, DNQX,

656 decreased the peak amplitude of the 2-AG transient ( $n=5$ slices, 1-way RM ANOVA,

657 Drug: $\left.F_{(2,8)}=56.91, p<0.0001\right)$. E) The NMDAR antagonist, DL-AP5, decreased the

658 peak amplitude of the 2-AG transient $\left(n=4\right.$ slices, 1 -way RM ANOVA, Drug: $F_{(2,6)}=$

$659 \quad 58.77, p<0.0001)$.

660

661 Figure 5. Muscarinic M1Rs are required for 2-AG generation evoked by brief synaptic

662 stimulation. A) The M1R antagonist VU'035, decreased the peak amplitude of the 2-AG

663 transient $\left(n=3\right.$ slices, 1 -way RM ANOVA, Drug: $\left.F_{(2,4)}=242.8, p<0.0001\right)$. B) The M1R

664 positive allosteric modulator VU'846 augmented the amplitude of the 2-AG transient $(n=$

6655 slices, 1-way RM ANOVA, Drug: $\left.F_{(2,8)}=13.36, p<0.01\right)$. 
667 Figure 6. M1Rs and mGlu1/5s trigger 2-AG mobilization through distinct mechanisms

668 that differentially require ionotropic glutamate receptors. A) Bath application of the

669 AMPAR antagonist, DNQX, blocks VU'846 augmentation 2-AG production ( $\mathrm{n}=3$ slices,

670 1-way RM ANOVA, Drug: $\left.F_{(2,4)}=685.7, p<0.0001\right)$. B) Bath application of the NMDAR

671 antagonist, DL-AP5, blocks VU'846 augmentation 2-AG production ( $\mathrm{n}=4$ slices, 1-way

672 RM ANOVA, Drug: $\left.\left.F_{(2,6)}=402.3, p<0.0001\right) . C\right)(R S)$-DHPG transiently augments 2-

673 AG production in the presence of DNQX ( $n=3$ slices, 1-way RM ANOVA, Drug: $F_{(2,4)}=$

674 52.17, $\mathrm{p}<0.0001)$.

675

676 Figure 7. D2Rs expressed on CINs inhibit 2-AG production. A) The D2R agonist,

677 quinpirole, decreased the peak amplitude of the evoked 2-AG transient and the D2R

678 antagonist, sulpiride, reversed the effect of quinpirole and increased the amplitude of

679 the 2-AG transient above baseline $\left(n=5\right.$ slices, 1 -way RM ANOVA, Drug: $F_{(2,8)}=29.59$,

$680 \mathrm{p}<0.001)$. B) Quinpirole reduced evoked ACh release, as measured with GRABACh3.0,

681 which was reversed by sulpiride $\left(n=4\right.$ slices, 1-way RM ANOVA, Drug: $F_{(2,6)}=10.99, p$

$682<0.01)$. C) Conditional knockout out of D2Rs on CINs precludes the effects of quinpirole

683 and sulpiride. ( $n=4 / 5$ slices/group, 2-way RM ANOVA, Drug: $F_{(14,98)}=10.23, p<$

684 0.0001; Genotype: $F_{(1,7)}=0.7338, p<0.05$; Interaction: $\left.F_{(14,98)}=15.14, p>0.0001\right)$.

686 Figure 8. Cartoon illustrating the circuit and cellular mechanisms underlying 2-AG

687 mobilization following brief synaptic stimulation. Our data are consistent with a model in 
which synaptic stimulation in the DLS generates 2-AG though converging glutamatergic

and cholinergic neurotransmission.

\section{References}

693 Ade, K.K., and Lovinger, D.M. (2007). Anandamide regulates postnatal development of long-

694 term synaptic plasticity in the rat dorsolateral striatum. J Neurosci 27, 2403-2409. Augustin, S.M., Chancey, J.H., and Lovinger, D.M. (2018). Dual Dopaminergic Regulation of Corticostriatal Plasticity by Cholinergic Interneurons and Indirect Pathway Medium Spiny Neurons. Cell Rep 24, 2883-2893. Bello, E.P., Mateo, Y., Gelman, D.M., Noain, D., Shin, J.H., Low, M.J., Alvarez, V.A., Lovinger, D.M., and Rubinstein, M. (2011). Cocaine supersensitivity and enhanced motivation for reward in mice lacking dopamine D2 autoreceptors. Nat Neurosci 14, 1033-1038. Brown, S.P., Brenowitz, S.D., and Regehr, W.G. (2003). Brief presynaptic bursts evoke synapsespecific retrograde inhibition mediated by endogenous cannabinoids. Nat Neurosci 6, 1048-1057. Calabresi, P., Maj, R., Pisani, A., Mercuri, N.B., and Bernardi, G. (1992). Long-term synaptic depression in the striatum: physiological and pharmacological characterization. J Neurosci 12, 4224-4233.

Calabresi, P., Picconi, B., Tozzi, A., and Di Filippo, M. (2007). Dopamine-mediated regulation of corticostriatal synaptic plasticity. Trends Neurosci 30, 211-219. Calabresi, P., Pisani, A., Mercuri, N.B., and Bernardi, G. (1994). Post-receptor mechanisms underlying striatal long-term depression. J Neurosci 14, 4871-4881. Chevaleyre, V., and Castillo, P.E. (2003). Heterosynaptic LTD of hippocampal GABAergic synapses: a novel role of endocannabinoids in regulating excitability. Neuron 38, 461-472. Choi, S., and Lovinger, D.M. (1997). Decreased probability of neurotransmitter release underlies striatal long-term depression and postnatal development of corticostriatal synapses. Proc Natl Acad Sci U S A 94, 2665-2670.

Costa, R.M., Cohen, D., and Nicolelis, M.A. (2004). Differential corticostriatal plasticity during fast and slow motor skill learning in mice. Curr Biol 14, 1124-1134.

Dong, A., He, K., Dudok, B., Farrell, J.S., Guan, W., Liput, D.J., Puhl, H.L., Cai, R., Duan, J., Albarran, E., et al. (2020). A fluorescent sensor for spatiotemporally resolved endocannabinoid dynamics in vitro and in vivo. bioRxiv, 2020.2010.2008.329169.

Fino, E., Paille, V., Cui, Y., Morera-Herreras, T., Deniau, J.M., and Venance, L. (2010). Distinct coincidence detectors govern the corticostriatal spike timing-dependent plasticity. J Physiol 588, 3045-3062.

Galante, M., and Diana, M.A. (2004). Group I metabotropic glutamate receptors inhibit GABA release at interneuron-Purkinje cell synapses through endocannabinoid production. J Neurosci 24, 4865-4874.

Gerdeman, G.L., Ronesi, J., and Lovinger, D.M. (2002). Postsynaptic endocannabinoid release is critical to long-term depression in the striatum. Nat Neurosci 5, 446-451. 
Giuffrida, A., Parsons, L.H., Kerr, T.M., Rodriguez de Fonseca, F., Navarro, M., and Piomelli, D. (1999). Dopamine activation of endogenous cannabinoid signaling in dorsal striatum. Nat

730 Neurosci 2, 358-363.

731 Gubellini, P., Saulle, E., Centonze, D., Bonsi, P., Pisani, A., Bernardi, G., Conquet, F., and Calabresi, P. (2001). Selective involvement of mGlu1 receptors in corticostriatal LTD. Neuropharmacology 40, 839-846. Heinbockel, T., Brager, D.H., Reich, C.G., Zhao, J., Muralidharan, S., Alger, B.E., and Kao, J.P. (2005). Endocannabinoid signaling dynamics probed with optical tools. J Neurosci 25, 94499459. Howe, A.R., and Surmeier, D.J. (1995). Muscarinic receptors modulate N-, P-, and L-type Ca2+ currents in rat striatal neurons through parallel pathways. J Neurosci 15, 458-469. Jing, M., Li, Y., Zeng, J., Huang, P., Skirzewski, M., Kljakic, O., Peng, W., Qian, T., Tan, K., Zou, J., et al. (2020). An optimized acetylcholine sensor for monitoring in vivo cholinergic activity. Nat Methods. Kano, M. (2014). Control of synaptic function by endocannabinoid-mediated retrograde signaling. Proc Jpn Acad Ser B Phys Biol Sci 90, 235-250. Kim, J., Isokawa, M., Ledent, C., and Alger, B.E. (2002). Activation of muscarinic acetylcholine receptors enhances the release of endogenous cannabinoids in the hippocampus. J Neurosci 22, 10182-10191.

Kreitzer, A.C., and Malenka, R.C. (2005). Dopamine modulation of state-dependent endocannabinoid release and long-term depression in the striatum. J Neurosci 25, 10537-10545. Kreitzer, A.C., and Regehr, W.G. (2001). Retrograde inhibition of presynaptic calcium influx by endogenous cannabinoids at excitatory synapses onto Purkinje cells. Neuron 29, 717-727. Kupferschmidt, D.A., and Lovinger, D.M. (2015). Inhibition of presynaptic calcium transients in cortical inputs to the dorsolateral striatum by metabotropic GABA(B) and mGlu $2 / 3$ receptors. J Physiol 593, 2295-2310.

Lee, S.H., Foldy, C., and Soltesz, I. (2010). Distinct endocannabinoid control of GABA release at perisomatic and dendritic synapses in the hippocampus. J Neurosci 30, 7993-8000.

Lee, S.H., Ledri, M., Toth, B., Marchionni, I., Henstridge, C.M., Dudok, B., Kenesei, K., Barna, L., Szabo, S.I., Renkecz, T., et al. (2015). Multiple Forms of Endocannabinoid and Endovanilloid Signaling Regulate the Tonic Control of GABA Release. J Neurosci 35, 1003910057.

Lerner, T.N., and Kreitzer, A.C. (2012). RGS4 is required for dopaminergic control of striatal LTD and susceptibility to parkinsonian motor deficits. Neuron 73, 347-359.

Liang, R., Broussard, G.J., and Tian, L. (2015). Imaging chemical neurotransmission with genetically encoded fluorescent sensors. ACS Chem Neurosci 6, 84-93.

Lovinger, D.M. (2008). Presynaptic modulation by endocannabinoids. Handb Exp Pharmacol, 435-477.

Maejima, T., Hashimoto, K., Yoshida, T., Aiba, A., and Kano, M. (2001). Presynaptic inhibition caused by retrograde signal from metabotropic glutamate to cannabinoid receptors. Neuron 31 , 463-475.

Maejima, T., Oka, S., Hashimotodani, Y., Ohno-Shosaku, T., Aiba, A., Wu, D., Waku, K., Sugiura, T., and Kano, M. (2005). Synaptically driven endocannabinoid release requires Ca2+assisted metabotropic glutamate receptor subtype 1 to phospholipase Cbeta4 signaling cascade in the cerebellum. J Neurosci 25, 6826-6835. 
Mathur, B.N., and Lovinger, D.M. (2012). Endocannabinoid-dopamine interactions in striatal synaptic plasticity. Front Pharmacol 3, 66. Mizuno, G.O., Unger, E.K., and Tian, L. (2019). Real Time Monitoring of Neuromodulators in Behaving Animals Using Genetically Encoded Indicators. In Compendium of In Vivo Monitoring in Real-Time Molecular Neuroscience, pp. 1-18.

Narushima, M., Uchigashima, M., Fukaya, M., Matsui, M., Manabe, T., Hashimoto, K., Watanabe, M., and Kano, M. (2007). Tonic enhancement of endocannabinoid-mediated retrograde suppression of inhibition by cholinergic interneuron activity in the striatum. J Neurosci 27, 496-506.

Neu, A., Foldy, C., and Soltesz, I. (2007). Postsynaptic origin of CB1-dependent tonic inhibition of GABA release at cholecystokinin-positive basket cell to pyramidal cell synapses in the CA1 region of the rat hippocampus. J Physiol 578, 233-247.

Ohno-Shosaku, T., Maejima, T., and Kano, M. (2001). Endogenous cannabinoids mediate retrograde signals from depolarized postsynaptic neurons to presynaptic terminals. Neuron 29 , 729-738.

Patel, S., Rademacher, D.J., and Hillard, C.J. (2003). Differential regulation of the endocannabinoids anandamide and 2-arachidonylglycerol within the limbic forebrain by dopamine receptor activity. J Pharmacol Exp Ther 306, 880-888.

Patriarchi, T., Cho, J.R., Merten, K., Howe, M.W., Marley, A., Xiong, W.H., Folk, R.W., Broussard, G.J., Liang, R., Jang, M.J., et al. (2018). Ultrafast neuronal imaging of dopamine dynamics with designed genetically encoded sensors. Science 360. Perez-Burgos, A., Perez-Rosello, T., Salgado, H., Flores-Barrera, E., Prieto, G.A., Figueroa, A., Galarraga, E., and Bargas, J. (2008). Muscarinic M(1) modulation of N and L types of calcium channels is mediated by protein kinase $C$ in neostriatal neurons. Neuroscience 155, 1079-1097. Ravotto, L., Duffet, L., Zhou, X., Weber, B., and Patriarchi, T. (2020). A Bright and Colorful Future for G-Protein Coupled Receptor Sensors. Front Cell Neurosci 14, 67. Ronesi, J., Gerdeman, G.L., and Lovinger, D.M. (2004). Disruption of endocannabinoid release and striatal long-term depression by postsynaptic blockade of endocannabinoid membrane transport. J Neurosci 24, 1673-1679. Ronesi, J., and Lovinger, D.M. (2005). Induction of striatal long-term synaptic depression by moderate frequency activation of cortical afferents in rat. J Physiol 562, 245-256. Sgobio, C., Kupferschmidt, D.A., Cui, G., Sun, L., Li, Z., Cai, H., and Lovinger, D.M. (2014). Optogenetic measurement of presynaptic calcium transients using conditional genetically encoded calcium indicator expression in dopaminergic neurons. PLoS One 9, e111749. Strobel, B., Miller, F.D., Rist, W., and Lamla, T. (2015). Comparative Analysis of Cesium Chloride- and Iodixanol-Based Purification of Recombinant Adeno-Associated Viral Vectors for Preclinical Applications. Hum Gene Ther Methods 26, 147-157. Sun, F., Zeng, J., Jing, M., Zhou, J., Feng, J., Owen, S.F., Luo, Y., Li, F., Wang, H., Yamaguchi, T., et al. (2018). A Genetically Encoded Fluorescent Sensor Enables Rapid and Specific Detection of Dopamine in Flies, Fish, and Mice. Cell 174, 481-496 e419. Sung, K.W., Choi, S., and Lovinger, D.M. (2001). Activation of group I mGluRs is necessary for induction of long-term depression at striatal synapses. J Neurophysiol 86, 2405-2412. Uchigashima, M., Narushima, M., Fukaya, M., Katona, I., Kano, M., and Watanabe, M. (2007). Subcellular arrangement of molecules for 2-arachidonoyl-glycerol-mediated retrograde signaling 8183676. 
819 Ueda, N., Tsuboi, K., and Uyama, T. (2013). Metabolism of endocannabinoids and related N820 acylethanolamines: canonical and alternative pathways. FEBS J 280, 1874-1894.

821 Wang, H., Jing, M., and Li, Y. (2018). Lighting up the brain: genetically encoded fluorescent 822 sensors for imaging neurotransmitters and neuromodulators. Curr Opin Neurobiol 50, 171-178.

823 Wang, W., Dever, D., Lowe, J., Storey, G.P., Bhansali, A., Eck, E.K., Nitulescu, I., Weimer, J., 824 and Bamford, N.S. (2012). Regulation of prefrontal excitatory neurotransmission by dopamine in 825 the nucleus accumbens core. J Physiol 590, 3743-3769.

826 Wang, Z., Kai, L., Day, M., Ronesi, J., Yin, H.H., Ding, J., Tkatch, T., Lovinger, D.M., and 827 Surmeier, D.J. (2006). Dopaminergic control of corticostriatal long-term synaptic depression in 828 medium spiny neurons is mediated by cholinergic interneurons. Neuron 50, 443-452.

829 Wilson, R.I., and Nicoll, R.A. (2001). Endogenous cannabinoids mediate retrograde signalling at 830 hippocampal synapses. Nature 410, 588-592.

831 Xiao, X., Li, J., and Samulski, R.J. (1998). Production of high-titer recombinant adeno832 associated virus vectors in the absence of helper adenovirus. J Virol 72, 2224-2232.

833 Yin, H.H., Davis, M.I., Ronesi, J.A., and Lovinger, D.M. (2006). The role of protein synthesis in 834 striatal long-term depression. J Neurosci 26, 11811-11820.

835 Yin, H.H., and Lovinger, D.M. (2006). Frequency-specific and D2 receptor-mediated inhibition 836 of glutamate release by retrograde endocannabinoid signaling. Proc Natl Acad Sci U S A 103, $837 \quad 8251-8256$. 
bioRxiv preprint doi: https://doi.org/10.1101/2020.10.21.348995; this version posted October 22, 2020. The copyright holder for this preprint (which was not certified by peer review) is the author/funder. This article is a US Government work. It is not subject to copyright under 17 USC 105 and is also made available for use under a CCO license.

Figure 1 $\begin{array}{cc}\text { AAV2/9.hSyn.GRABeCB2.0 } & \text { Slice photometry in DLS } \\ \text { in motor cortex (M1/M2) } & \text { w/electrical stimulation }\end{array}$

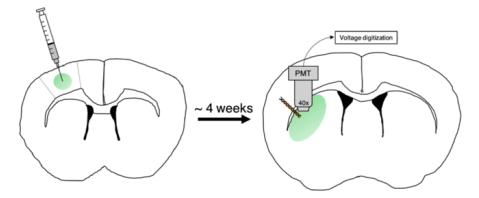

B

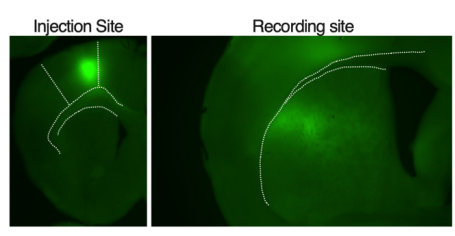

C

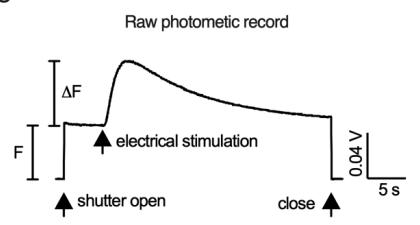

Normalized endocannabinoid transient

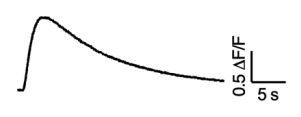

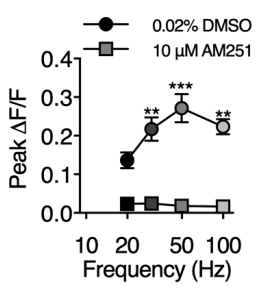

E

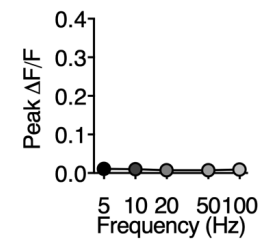

$0.02 \%$ DMSO

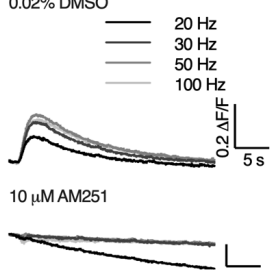

GRABeCBMUT $-5 \mathrm{~Hz}$

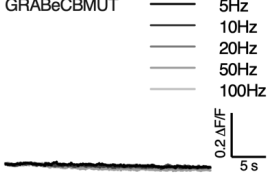


bioRxiv preprint doi: https://doi.org/10.1101/2020.10.21.348995; this version posted October 22,2020 . The copyright holder for this preprint (which was not certified by peer review) is the author/funder. This article is a US Government work. It is not subject to copyright under 17 USC 105 and is also made available for use under a CCO license.

Figure 2

A

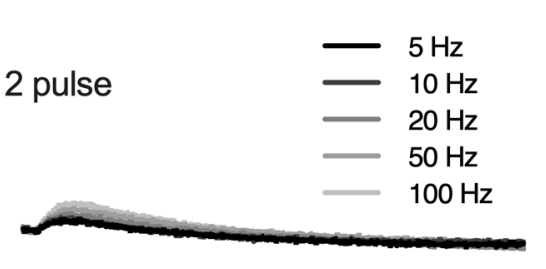

5 pulse

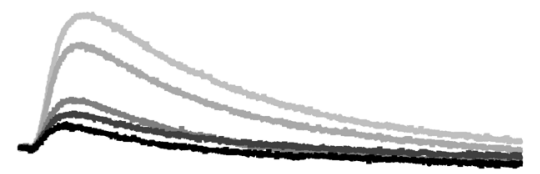

10 pulse

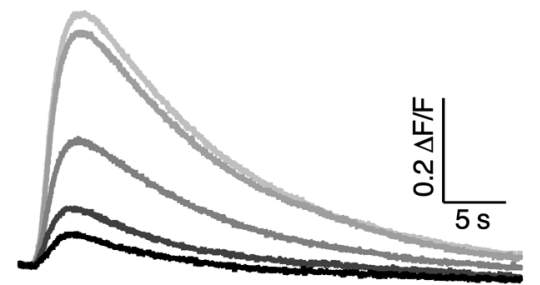

E

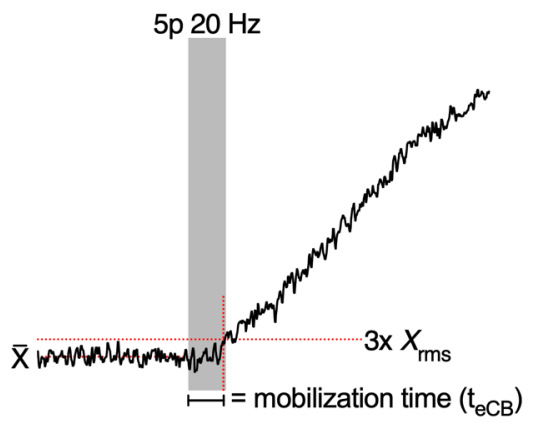

B

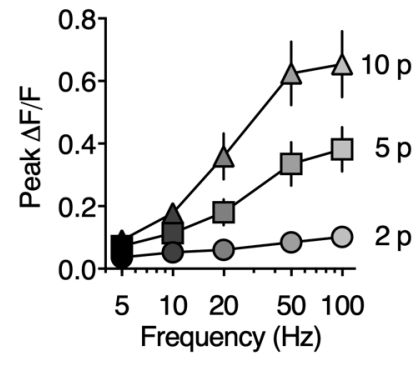

C

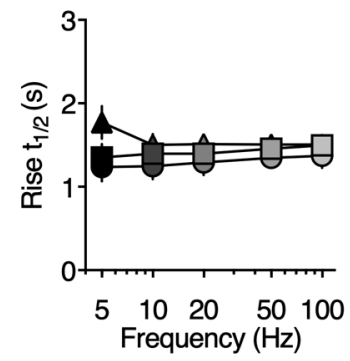

D

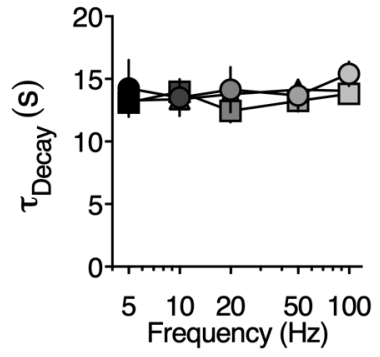

F

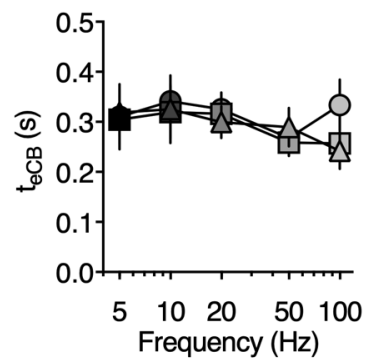


bioRxiv preprint doi: https://doi.org/10.1101/2020.10.21.348995; this version posted October 22, 2020. The copyright holder for this preprint (which was not certified by peer review) is the author/funder. This article is a US Government work. It is not subject to copyright under 17 USC 105 and is also made available for use under a CCO license.

\section{Figure 3}

A

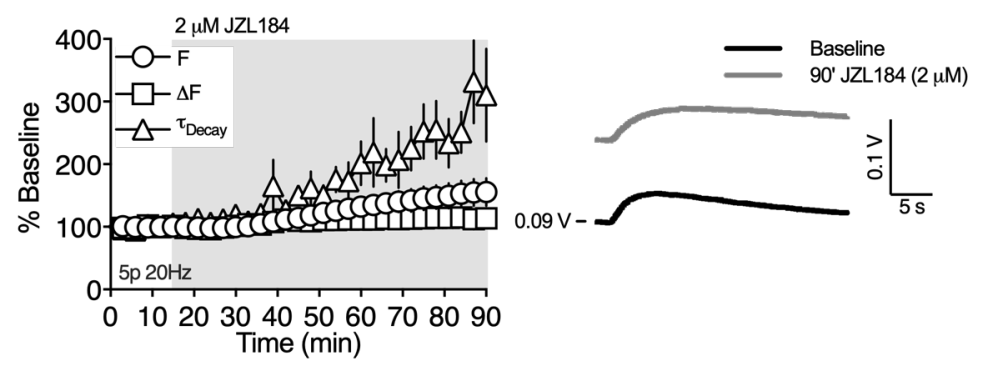

B
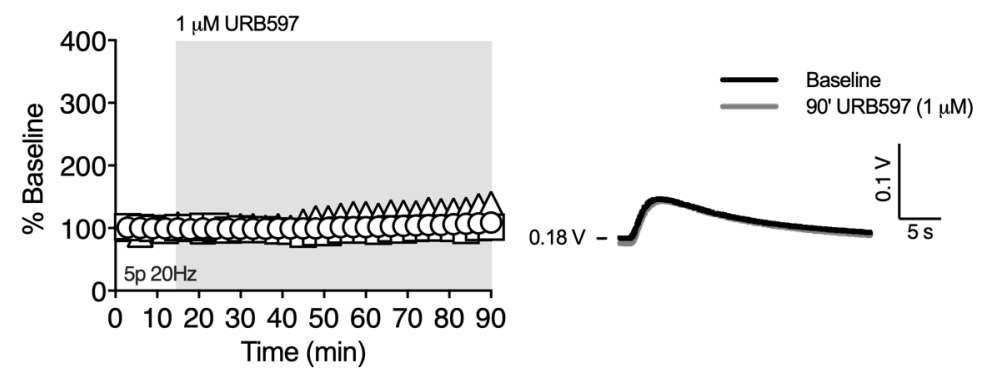

C
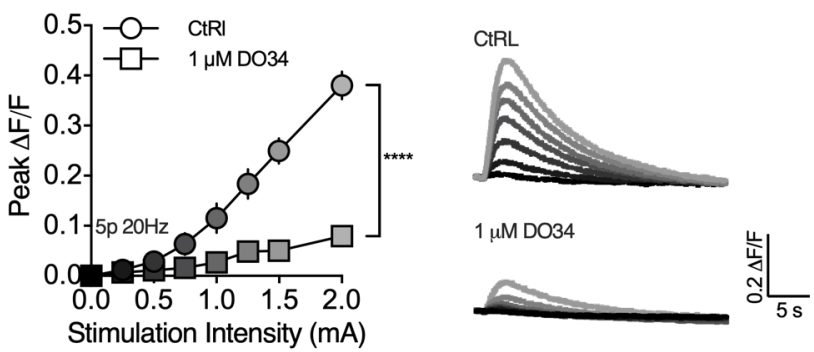
bioRxiv preprint doi: https://doi.org/10.1101/2020.10.21.348995; this version posted October 22, 2020. The copyright holder for this preprint (which was not certified by peer review) is the author/funder. This article is a US Government work. It is not subject to copyright under 17 USC 105 and is also made available for use under a CCO license.

Figure 4

A

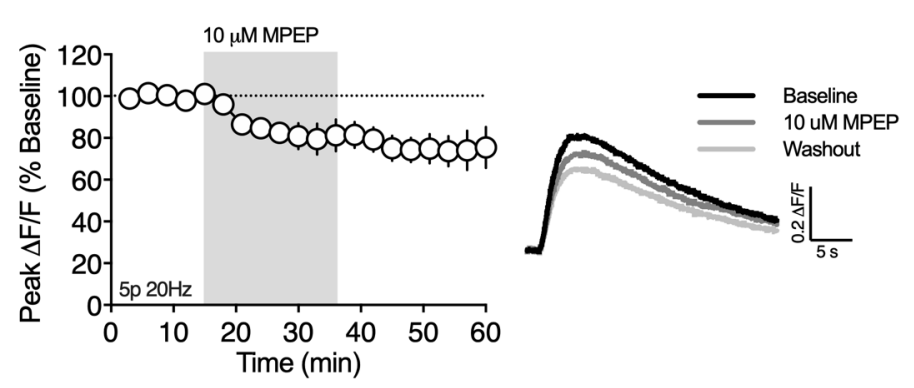

B

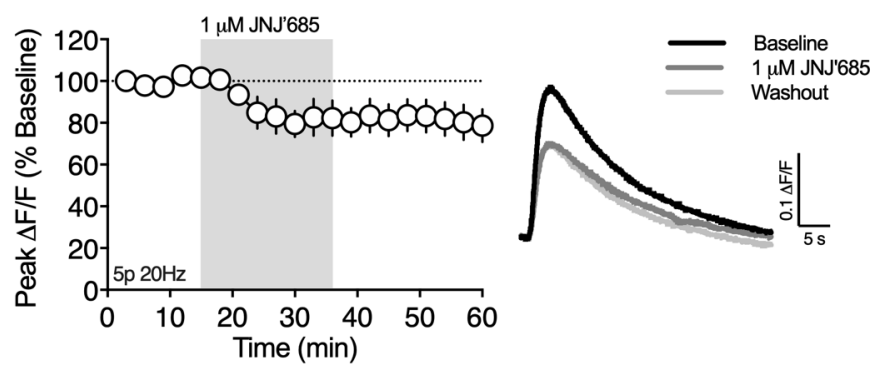

C

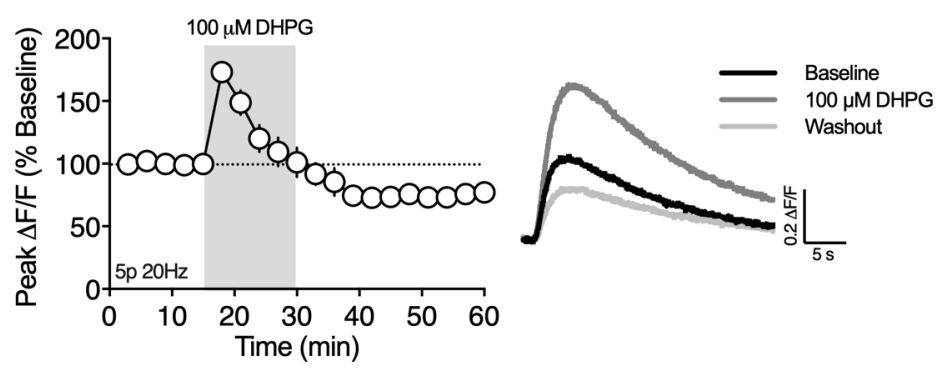

D

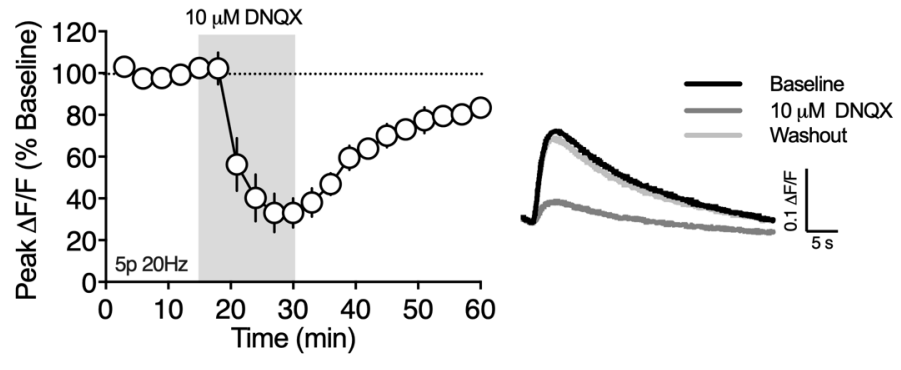

$\mathrm{E}$

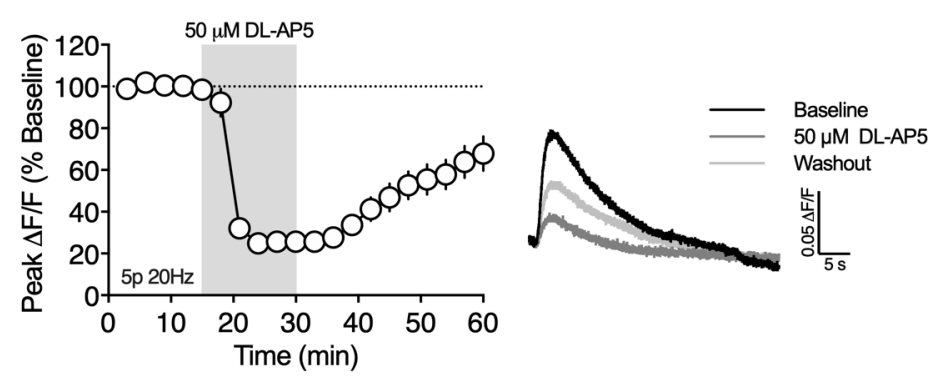


bioRxiv preprint doi: https://doi.org/10.1101/2020.10.21.348995; this version posted October 22, 2020. The copyright holder for this preprint (which was not certified by peer review) is the author/funder. This article is a US Government work. It is not subject to copyright under 17 USC 105 and is also made available for use under a CCO license.

\section{Figure 5}

A

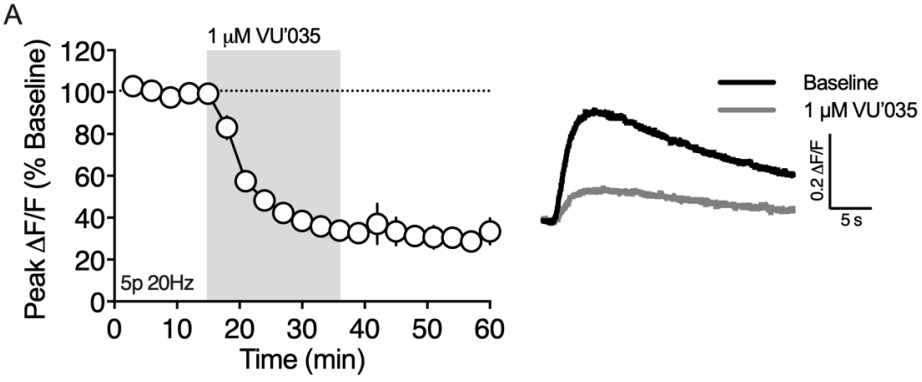

B

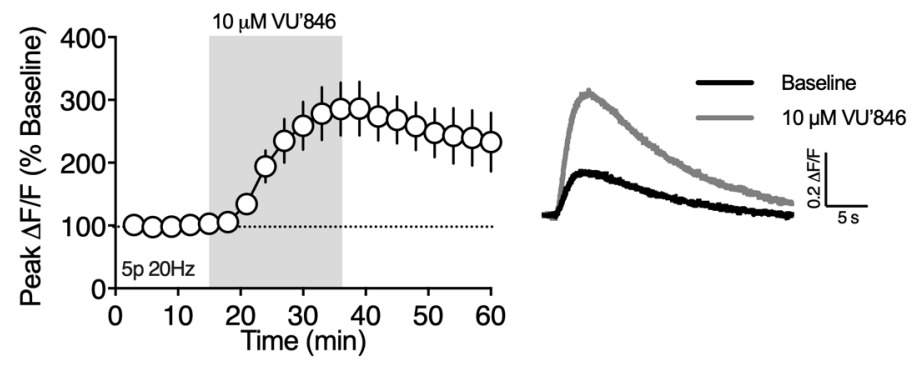


bioRxiv preprint doi: https://doi.org/10.1101/2020.10.21.348995; this version posted October 22, 2020. The copyright holder for this preprint (which was not certified by peer review) is the author/funder. This article is a US Government work. It is not subject to copyright under 17 USC 105 and is also made available for use under a CCO license.

Figure 6

A

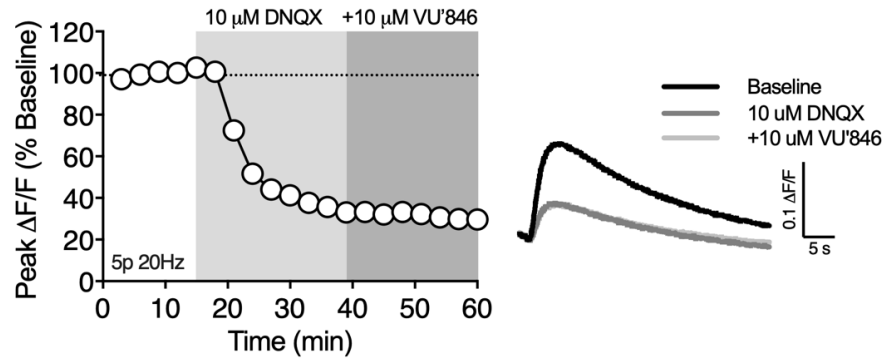

B

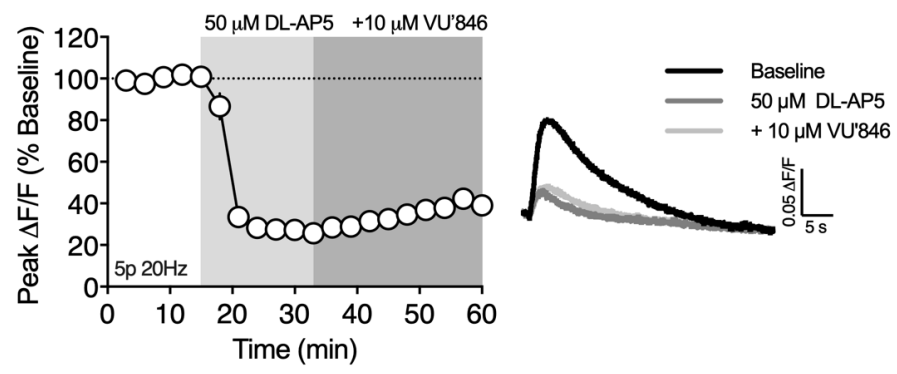

C

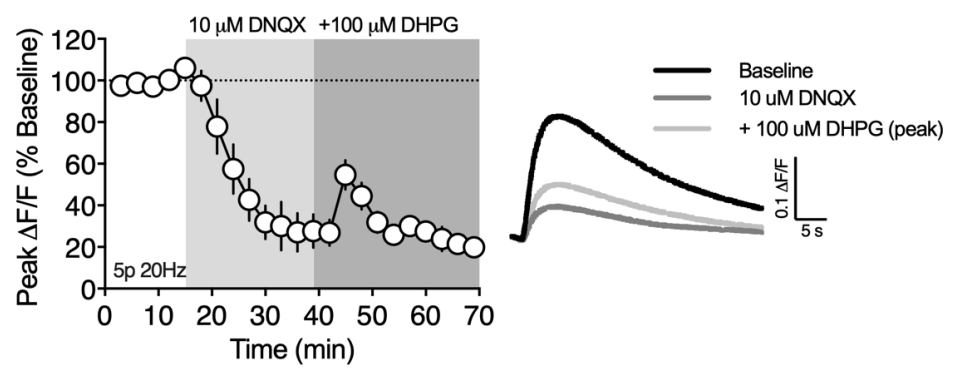


bioRxiv preprint doi: https://doi.org/10.1101/2020.10.21.348995; this version posted October 22, 2020. The copyright holder for this preprint (which was not certified by peer review) is the author/funder. This article is a US Government work. It is not subject to copyright under 17 USC 105 and is also made available for use under a CCO license.

Figure 7

A

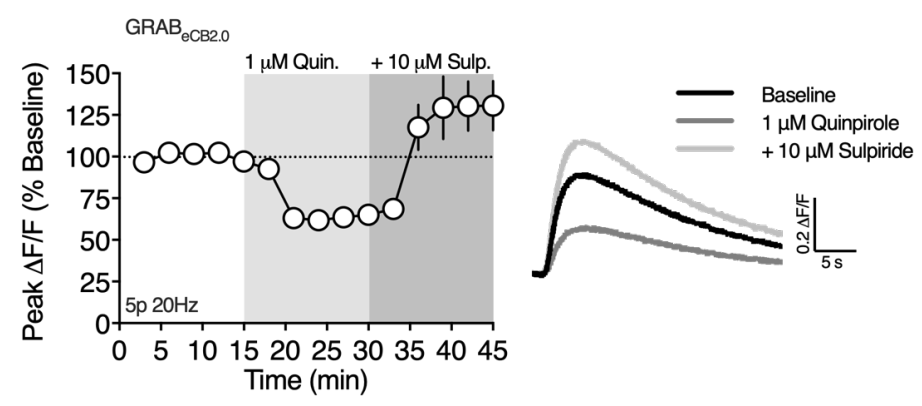

B

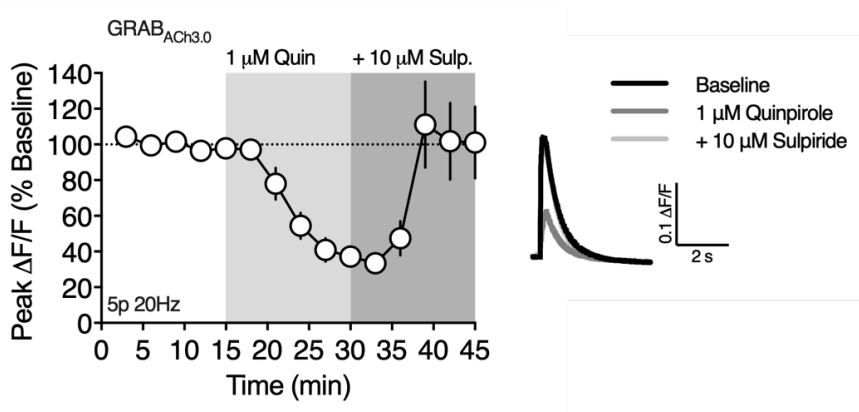

C

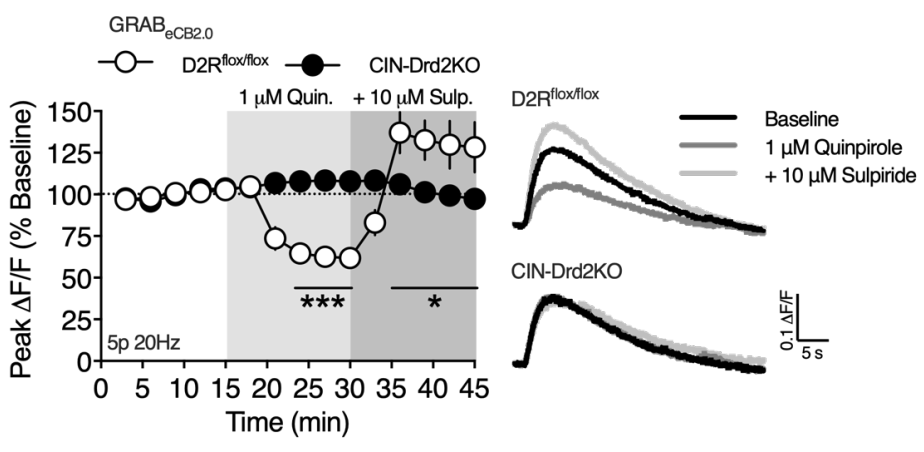


bioRxiv preprint doi: https://doi.org/10.1101/2020.10.21.348995; this version posted October 22, 2020. The copyright holder for this preprint (which was not certified by peer review) is the author/funder. This article is a US Government work. It is not subject to copyright under 17 USC 105 and is also made available for use under a CCO license.

Figure 8

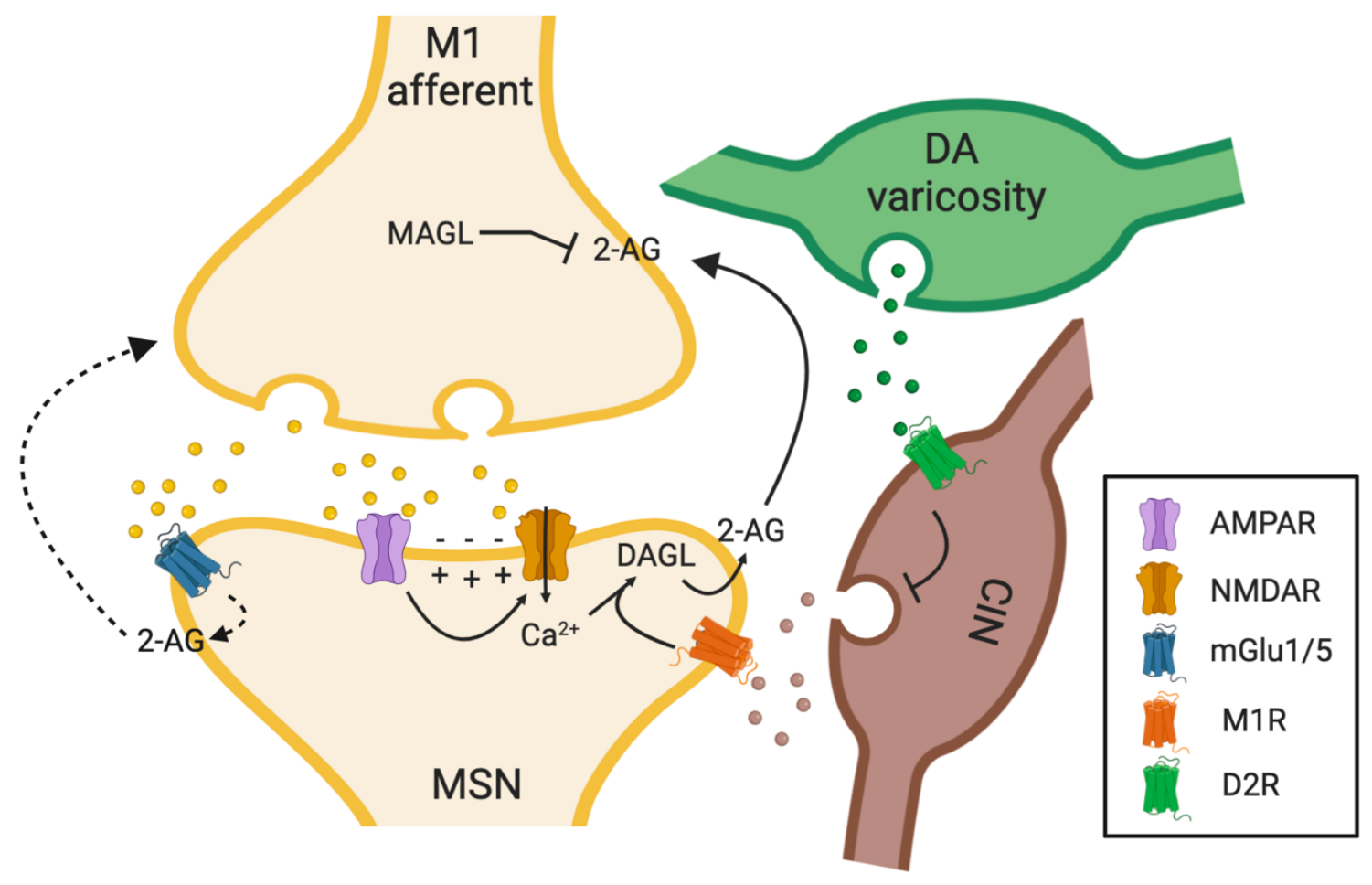

